\title{
SECURITIZATION AND ASSET PRICES 2015
}

Yunus Aksoy and Henrique S. Basso.

Documentos de Trabajo. N. 1526

\section{BaNCo Gespaña}

\author{
Eurosistema
}


SECURITIZATION AND ASSET PRICES ${ }^{(*)}$

\author{
Yunus Aksoy ${ }^{(*)}$ \\ BIRKBECK, UNIVERSITY OF LONDON \\ Henrique S. Basso $\left.{ }^{(\star \star}\right)$ \\ BANCO DE ESPAÑA
}

(*) We would like to thank, without implicating, Georgy Chabakauri, Tomek Piskorski, Pavol Povala, Colin Rowat, Ron P. Smith, Adi Sunderam and seminar participants at the City University London, University of St Andrews, University of Glasgow, Banco de España, the CESifo Area Conference on Macro, Money and International Finance 2014 in Munich, BCAM conference at Birkbeck, BMRC-DEMS Conference at Brunel University, MMF Conference in Durham, CEF 2014 conference in Oslo, LAMES 2014 meeting in Sao Paulo, ASSA 2015 meeting in Boston, Royal Economic Society 2015 meeting in Manchester, the XXIII Finance Forum in Madrid and the Econometric Society World Congress in Montreal for helpful comments. The views expressed in this paper are those of the authors and do not necessarily coincide with those of the Banco de España or the Eurosystem. Yunus Aksoy and Henrique S. Basso are also aliated with the Birkbeck Centre for Applied Macroeconomics (BCAM).

(**) Department of Economics, Mathematics and Statistics, Birkbeck, University of London, Malet Street, WC1E 7HX, London, United Kingdom, Tel: +44 207631 6407, Fax: +44 207631 6416, e-mail: y.aksoy@bbk.ac.uk ${ }^{(\star \star *)}$ Banco de España, Alcalá 48, 28014 Madrid, Spain. e-mail: henrique.basso@bde.es 
The Working Paper Series seeks to disseminate original research in economics and finance. All papers have been anonymously refereed. By publishing these papers, the Banco de España aims to contribute to economic analysis and, in particular, to knowledge of the Spanish economy and its international environment.

The opinions and analyses in the Working Paper Series are the responsibility of the authors and, therefore, do not necessarily coincide with those of the Banco de España or the Eurosystem.

The Banco de España disseminates its main reports and most of its publications via the Internet at the following website: http://www.bde.es.

Reproduction for educational and non-commercial purposes is permitted provided that the source is acknowledged.

C BANCO DE ESPAÑA, Madrid, 2015

ISSN: 1579-8666 (on line) 


\section{Abstract}

We investigate the link between securitization and asset prices and show that increases in the growth rate of the volume of ABS issuance lead to a sizable decline in bond and equity premia. Furthermore, we show that in a model where banks select their portfolio of assets and create synthetic securities, the compensation for undertaking risk decreases as securitization increases. The pooling and tranching of credit assets relaxes both the funding and the risk constraints banks face allowing them to increase balance sheet holdings. Accordingly, the drop in risk premium may be unrelated to a decline in actual risk.

Keywords: pooling and tranching, equity, government bonds, bank portfolio, risk premia.

JEL classification: E44, G12, G2. 


\section{Resumen}

Este trabajo analiza la relación entre el volumen de titulización de activos de crédito y los precios de bonos y acciones. Se muestra que aumentos en la tasa de crecimiento de titulización generan una disminución considerable en primas en el mercado de bonos y de renta variable. En un modelo teórico se demuestra que cuando los bancos seleccionan su cartera de activos y crean activos sintéticos, la compensación por la exposición al riesgo en la economía disminuye en la medida que aumenta la titulización. La agregación y la división en tramos de activos crediticios relajan tanto los costes de financiación como la exposición al riesgo de los bancos, lo que permite aumentar la cartera de activos a bancos que mantienen una cartera diversificada. Por tanto, es posible que la disminución de la prima de riesgo no identifique la verdadera disminución en la exposición al riesgo de los activos en el mercado de bonos y de renta variable.

Palabras clave: agregación y división en tramos, acciones en el mercado de renta variable, bonos del Gobierno, cartera de los bancos, prima de riesgo.

Códigos JEL: E44, G12, G2. 


\section{Introduction}

The volume of securitized assets traded in the US has grown remarkably from the beginning of the 1990s until the onset of the global financial crisis, when it collapsed. Figure 1 shows the monthly volume of issuance of asset-backed securities $(A B S)$, mortgagebacked securities $(M B S)$ and their sum (all) from January 1993 until December 2010. Such volumes have been determinant in shaping the development of financial markets and particularly financial intermediation, motivating several studies to analyse their effects on credit issuance and standards, focusing particularly on mortgage markets. The general message is that mortgage securitization increases loan supply and lowers aggregate price of credit. Although securitization has traditionally been higher in the mortgage market, our data shows that the issuance of ABS matches the issuance of $M B S$ in the beginning of the 2000's. Furthermore, the participants in the market for asset-backed securities are financial entities, comprising financial companies and funding corporations, sometimes referred to as shadow banks, who hold a more diverse portfolio than commercial banks. As a result, due to potential portfolio effects, those high volumes of securitization might affect other asset classes. The focus of this paper, therefore, is to investigate the effects of securitization on bond and equity markets.

Figure 1: Volume of Securitization - US

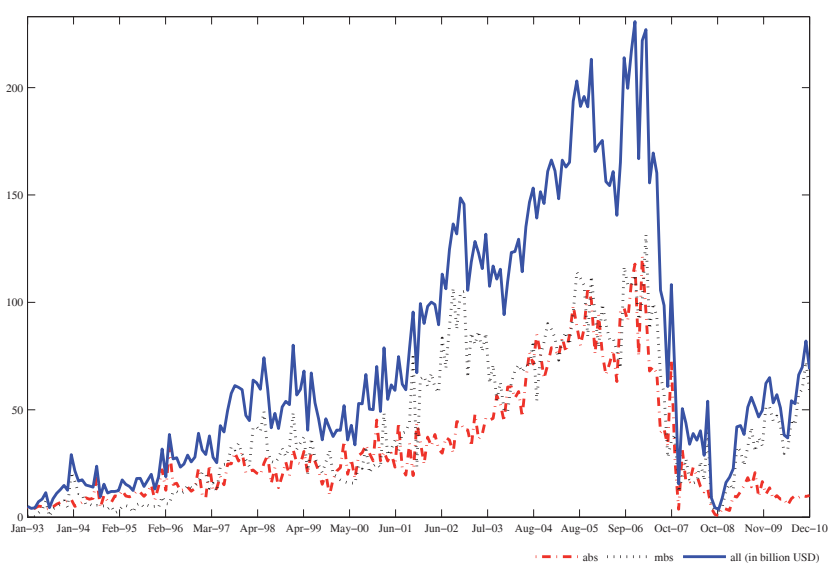

We first conduct an empirical analysis that looks at the dynamic properties of bond and equity excess returns (risk premia ${ }^{1}$ ) and identify the effects of variations in the volume of securitization on asset prices. The benchmark empirical specification builds upon the work of Campbell, Chan, and Viceira (2003), and sets up a general vector autoregressive (VAR) process for asset returns including the volume of securitization, the bond premium and the equity premium. Additionally, as they do, we include the short-term rate, the dividend-

\footnotetext{
${ }^{1}$ We will use excess returns and risk premia interchangeably. Note that in some studies risk premia is defined as the expected excess return.
} 
price ratio and the yield spread. We find that an innovation to the growth of asset-backed securitization leads to a statistically and economically significant drop in term spreads, equity and bond premium and contribute to explain their variance. A monthly increase of 5 billion USD in the volume of ABS issued in the market leads to a 5 basis point movement in bond premium and a 272 basis point decrease in equity premium. Although the benchmark empirical analysis focuses on the period before the crisis, we find that the relationship between securitization and asset prices seem to hold also for the post-crisis period (after 2008). We then augment the model in order to detect whether this link is related to financial intermediation or whether securitization might be instrumenting for other aspects of the economy or the financial markets. For this purpose we include a wide range of control variables in our estimations next to securitization measures. For instance, we control for risk perceptions/aversion (vix), for the Cochrane-Piazessi factor (CP) in order to account for the consumer's heteroscedastic discount factor as suggested by Cochrane and Piazzesi (2005), for expectations about economic performance, for changes in credit conditions (credit spread) and equity payoff (expected earnings-per-share). Additionally we control for international U.S. asset demand and corporate bond issuance. Our results remain by and large unaltered and thus indicate that specific aspects of financial intermediation that are related to fluctuations in securitization affect prices and volumes of different asset classes other than credit in a significant way.

While comparing the effects of different segments of the securitization market we find that the link between securitization and asset prices is stronger with asset-backed securities than with mortgage-backed securities. We believe that this is because shadow banks and securities and broker-dealers became important players in the $A B S$ market reinforcing the view that the effect occurs through the portfolio allocation changes due to securitization. Data from the Federal Reserve Bank Flow of Funds on total asset holdings and their growth during the 90's and 2000's, depicted in Figure 2, confirms the importance of these financial entities $^{2}$ relative to commercial banks and other sectors in the economy (households and non-financial firms). Note that the accumulation of assets of these entities is very much linked to the volume of securitized assets issued in the US market. The growth of assets is faster during the 90's as volume of securitization quickly reached around 50 billion USD per month. After that, the growth rate of assets decreases during the early 2000's while monthly volumes of issuance in the securitization markets remained fairly constant. Asset holdings start to increase sharply again during the next period of growth in the securitization market, from 2002/2003 till 2006/2007, when monthly issuance reached 200 billion USD. In fact, when we include both securitization and security and broker dealers asset holdings in our (quarterly) VAR specification we confirm this link, an innovation to the asset backed securitization leads to a sharp increase in asset holdings. Finally, using

\footnotetext{
${ }^{2}$ Shadow banks comprise of financial companies, funding corporations and ABS issuers. We then add securities and broker-dealers and compare their total to that of commercial banks.
} 
our quarterly specification we observe that our results are unaltered when we incorporate banking capital in our estimations.

Figure 2: Increasing Relevance of Financial Sector

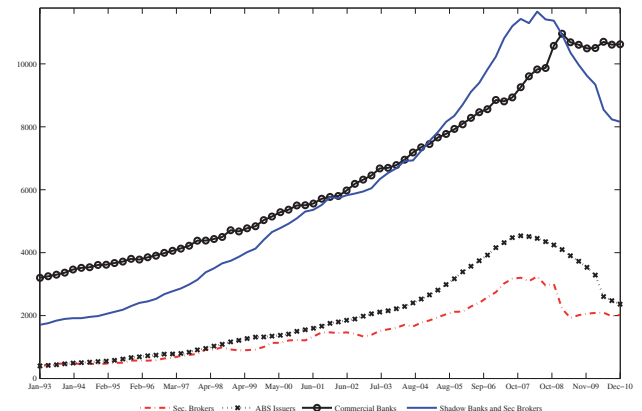

(a) Financial Assets - Commercial vs Shadow Banks

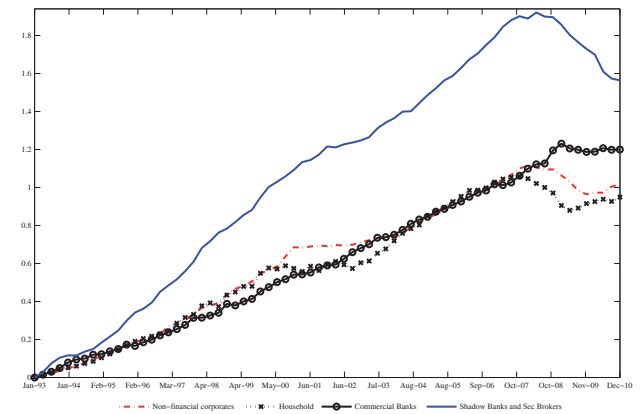

(b) Growth of Assets in Different Sectors

We then propose a theoretical model that can account for our empirical findings and use it to discuss the channels through which financial intermediation and particularly, securitization practices, affect asset prices and risk premia. The model's two key ingredients are: banks ${ }^{3}$ can create a market for securitized assets by designing and selling synthetic securities (securitization decision), and select which assets to hold in their balance sheet (portfolio decision). In creating the securitization market we follow DeMarzo and Duffie (1999) closely and motivate the issuance of synthetic securities as a tool to create liquidity. Banks select the allocation of assets to maximize expected returns subject to two constraints: they must fund all purchases with internal and with, potentially costly, external funds and they must abide by a risk constraint. We find that securitization, or the pooling and tranching of credit assets, allows banks to expand their balance sheets since it not only relaxes the banks' cash or funding constraint but also their risk constraint. As a result, securitization allows banks to take additional exposures not only on credit but also on bonds and equity. The desire to increase exposure in all asset classes stems from the fact that concentrating asset holdings in one class depresses returns and, due to lack of diversification, increases the shadow cost of risk. Greater asset demand increases prices and depresses risk premia, confirming the empirical results.

One of the implications of the theoretical model is that although the intrinsic characteristics of assets, their return and risk profile, have not changed, and the degree of risk aversion has remained the same, higher volumes of securitization decrease the compensation for risk bearing in the economy. In other words, there is a potential mismatch between actual and market price of risk due to securitization process. As pointed out by Rajan (2005), reduced premia/volatility does not directly imply reduction in risk.

\footnotetext{
${ }^{3}$ Unless otherwise specified banks are generic financial entities holding a diversified portfolio of assets and engage in financial intermediation.
} 
The framework also corroborates the importance of financial intermediation in determining asset prices. As financial intermediation is linked with asset prices through the functioning of the securitization market we can use the structural characteristic of this market to understand the channels through which this link occurs. The volume of securitization in our model is primarily linked to the degree of asymmetric information. Focusing on informational issues also allow us to stress the optimality of pooling and tranching, key components behind the portfolio mechanism we propose. However, the framework also highlights other drivers of the volume of securitization, for instance, the degree of riskiness of credit baskets and the compensation to undertake tranche related risk. While the volume of deals might be influenced by a variety of factors, as long as pooling and tranching is done, allowing banks to relax cash and risk constraints, the portfolio mechanism highlighted here establishes a link between the variation in the volume of securitization (and those factors) and bond and equity premia.

\section{Related Literature}

Our work is connected to three main streams of literature. Firstly, it is linked to the empirical literature that studies the effect of securitization on credit market outcomes. Loutskina and Strahan (2009) show that credit supply is sensitive to lender's funding restrictions for illiquid loans, classified as such since they cannot be securitized, but is not for their liquid counterpart. Hence, their results indicate that high levels of securitization in the US would lead to higher loan supply. Altunbas, Gambacorta, and Marques-Ibanez (2009) look at the banking sector in Europe and conclude that securitization has strengthened banks' capacity to supply new loans. Finally, Jiménez, Mian, Peydró, and Saurina (2010), by using data from Spain, conclude that wholesale finance allows banks with access to securitization to increase their credit supply and decreases the aggregate price of credit. In all cases, including ours, the common feature is that securitization leads to a balance sheet expansion of banks. However, these studies look at credit markets only, while we attempt to look at the impact of securitization on other asset classes.

The second and main literature that our paper relates to is the one that focuses on the effect of financial intermediation on asset prices. He and Krishnamurthy (2013) show that, during periods of crisis, binding banking capital constraints help to explain the evolution of risk premia. Our results indicate that different characteristics of financial intermediaries' balance sheets can be relevant in asset pricing even when banking capital is not a direct concern. Adrian, Etula, and Muir (2014) and Adrian, Moench, and Shin (2010) stress that the growth of assets in the balance sheet of security and broker-dealers influences asset prices and risk premia. These studies are the closest to ours since as the data shows securitization and balance sheet expansion of these entities are closely linked. Our added contribution is that, by looking closely at the portfolio choice of financial intermediaries and incorporating one of the key aspects in their decision, namely, the ability to create and sell synthetic assets, we are able to identify the potential channels and structural parameters that link financial intermediation and asset prices. Finally, Aksoy and Basso (2014) 
also explore the effects of bank's portfolio choice but focus on maturity transformation and the gap between long and short-term interest rates in a general equilibrium setting, linking financial intermediation with fluctuations in term premia.

Lastly, our paper relates to the literature that analyse leverage cycles. Danielsson, Shin, and Zigrand (2012) provide a framework linking financial intermediation, leverage, volatility and risk premium, stressing the role of bank's balance sheet in asset price determination. However, their mechanism relies on fluctuations in bank capital. Leverage in our framework fluctuates as an outcome of the securitization markets while bank equity is held constant. In fact we show that our empirical results remain the same when we control for movements in banking capital. Fostel and Geanakoplos (2012) also look at financial innovations and leverage, and as here stress the importance of tranching to generate leverage. However, they focus on the final investors' demand based on heterogenous beliefs leading to asset price bubbles while we focus on the the importance of pooling and tranching in shaping the portfolio decisions of banks, establishing a link between financial intermediation and asset prices.

The paper is organized as follows. Section 2 presents our empirical analysis. The theoretical model and its solution are presented in Section 3. Section 4 discusses the main implications of our results. Finally, Section 5 concludes.

\section{Empirical Analysis}

Our empirical analysis focuses on establishing whether variations in the volume of securitized credit assets affect different asset markets, particularly by looking at the dynamic patterns of risk premia in fixed income and equity markets. Our starting point is a general vector autoregression (VAR) for asset returns used by Campbell and Viceira (1999) and Campbell, Chan, and Viceira (2003). Campbell, Chan, and Viceira (2003) employ a VAR containing the returns of the main fixed income and equity assets, namely the short-term rate, the excess return on government bond (bond premium) and the equity excess return (equity premium). Additionally, they include the dividend-price ratio and the yield/term spread (difference between short and long term rates). Given our focus on securitization we add the variation in the volume of securitized assets traded as an additional variable. Our main interest, therefore, is in assessing whether there is additional information content in fluctuations in securitization for explaining variations in excess market and bond returns and establishing the effect of a shock to this additional variable on the dynamic responses of asset returns. In order to identify these shock responses we follow the identification structure of Christiano, Eichenbaum, and Evans (1999). As such, the VAR moving average representation is given by

$$
\mathbf{z}_{t}=\mathbf{B}(L) \mathbf{u}_{t},
$$


where $\mathbf{B}(L)$ is the matrix of moving average coefficients and $\mathbf{z}_{t}^{\prime}=\left[\mathbf{x}_{1 t}^{\prime}, \varpi_{t}^{i \prime}, \mathbf{x}_{2 t}^{\prime}\right]$ the vector of observables. $\varpi_{t}^{i}$ represents the securitization measure we use, with $i=\left\{d A B S_{t}\right.$, $\left.d M B S_{t}, d A L L s_{t}\right\}$ for asset backed securitization, mortgage backed securitization and aggregate securitization, used one at a time. Note that $\mathbf{x}_{1 t}$ is a $\left(k_{1} \times 1\right)$ vector with elements whose contemporaneous and lagged values influence the variables of interest at time $t$ and $\mathbf{x}_{2 t}$ is a $\left(k_{2} \times 1\right)$ vector with elements whose values are only affected by an innovation to the variables of interest at time $t$. Finally, $\mathbf{u}_{t}$ is a $(k \times 1)$ vector of reduced form errors with $k=k_{1}+1+k_{2}$. We want to obtain an impact matrix $\overline{\mathbf{A}}$ linking reduced form errors $\left(\mathbf{u}_{t}\right)$ to fundamental shocks $\left(\varepsilon_{t}\right)$ such that $\mathbf{u}_{t}=\overline{\mathbf{A}} \varepsilon_{t}$. We assume that $\overline{\mathbf{A}}$ has a block triangular structure with zero in its upper diagonal.

For our benchmark analysis, we assume $\mathbf{x}_{1 t}$ is empty, placing all remaining variables in $\mathbf{x}_{2 t}$, hence the securitization variable is ordered first, being unaffected by the other variables contemporaneously. This identification assumption reflects the fact that the securitization process normally requires the creation of a new accounting entity (special purpose vehicles) that holds and commercializes the assets and the pooling and tranching of assets that are then rated by external credit agencies. As a result, it involves a time delay from decision to implementation greater than the reaction time of asset prices. Thus, it appears natural to assume that asset prices can only affect the volume of securitization with a lag. ${ }^{4}$

Campbell, Chan, and Viceira (2003) employs a first-order VAR using a relatively long dataset of quarterly or annual frequency. As shown in the introduction, the development of the securitization market is a recent event (last 15-20 years). Moreover, given our identification and the fact that a bank's portfolio selection should occur at much shorter frequency, we use a monthly dataset. As a result, in order to capture sufficient dynamics (particularly in fixed income return) we estimate the model with four lags. We calculate impulse responses to a securitization shock and associated one standard error bias-corrected bootstrap confidence bands as suggested by Kilian (1998). Before discussing the estimation results we present the dataset.

\subsection{Data}

Our securitization data, obtained from Dealogic ${ }^{5}$, consists of daily data on asset $(A B S)$ and mortgage backed securitization $(M B S)$ with tranche values and deal dates completed in the US from the year 1993 onwards. Using this dataset, we are able to construct monthly time series data of the volume of transacted securities in the US financial markets. Figure 1 (depicted in the introduction) displays the levels data for both $A B S$ and $M B S$

\footnotetext{
${ }^{4}$ Note that we use the face value and not the proceeds of each deal to construct our variable and thus fluctuations at auction day do not affect our measure of securitization.

${ }^{5}$ We obtain a deal report with deal type equal to ABS or MBS, currency code equal to USD, nationality of risk equal to USA and deal price date from beginning of 1993 until October 2014.
} 
securitization volumes and an aggregate measure (all), with their summation. As is clear from the figure, while securitization started from rather modest levels by early 1990s, aggregate securitization steadily increased reaching their peak in March 2007. ${ }^{6}$ Figure 1 suggests that there is a structural break in the securitization process in 2007 where market of synthetic securities froze and financial institutions and/or final investors started to move away from the practice. This is long before the full blown realization of the financial crisis in September 2008 triggered by the collapse of Lehman Brothers.

In the VAR, we include seasonally adjusted asset and mortgage backed securitization transformed in annualized monthly log differences in percentage terms, denoting them respectively, $d A B S$ and $d M B S .{ }^{7}$ We also construct a monthly aggregate securitization series (alls) being the simple sum of $M B S$ and $A B S$ (labelled as $d A L L s$ ). Next to the securitization data, our empirical exercise utilizes the following data series. Benchmark monthly excess market returns $(x r)$ annualized, obtained from the Kenneth French website, are based on Fama-French method and summarize the excess return on the (equity) market over the risk free rate (3 months T-Bill rate). We use monthly Fama-Bliss Discount Bonds as reported by CRSP to calculate annual excess bond returns ( $x b r$ ) over 2,3,4 and 5 years horizons as described in Gurkaynak, Sack, and Wright (2007) for the calculation of yields and in Cochrane and Piazzesi (2005) for the calculation of the excess bond returns, i.e. $x b r_{t+1}^{(n)}=r_{t+1}^{(n)}-y_{t}^{(1)}$ where $x b r_{t+1}^{(n)}$ denotes the $n$ year excess log return, $r_{t+1}^{(n)}$ denotes the log holding period return from buying an $n$-year bond at time $t$ and selling it as $n-1$ year bond at time $t+1$ and $y_{t}^{(1)}$ denotes the log yield. We use monthly real price dividend ratio $(r p d)$ that is calculated using the log difference in real dividends and real stock prices (S\&P Composite Stock Price Index) as reported and updated by Robert Shiller's stock market data. Term spreads (spread) are computed as the difference between the five year government bond rate and 3 months T-Bill in percentages per annum. Real short term rates (realr_3m) are calculated using the 3 months T-Bill rate and the CPI inflation. Our full sample covers the period from January 1993 up until October 2014. However, conditional mean and variances have most likely changed as a result of the financial crisis and central bank intervention, which influenced market liquidity and consequently the securitization market, preventing us from estimating the full period without accounting for the regime change. In order to do so we would need a longer post-crisis dataset than we currently have. As a result, in our benchmark VAR estimations we only use data from

\footnotetext{
${ }^{6}$ We note that the asset backed securitization increased from a monthly average of 5.2 billion USD in 1993 to 86.4 billion USD in 2006 (a 1540\% increase) and the mortgage backed securitization increased from a monthly average of 3.5 billion USD in 1993 to 93.4 billion USD in 2006 (a 2603\% increase). By the second quarter of 2007 both securitization markets collapsed and volumes remained at much lower levels as compared to pre-crisis period.

${ }^{7}$ We use Census X12 method to remove cyclical seasonal movements from securitization series and to extract the underlying trend component. In our estimations we also use non-adjusted series to check for the robustness of the results. Our results by and large do not change.
} 
January 1993 till November 2007; thereby we exclude the period after the collapse of the securitization market that later on became a full blown financial crisis. ${ }^{8}$

\subsection{Estimation Results - Parsimonious model}

As mentioned before our starting point is a parsimonious representation of asset returns provided by Campbell, Chan, and Viceira (2003). We therefore set up the benchmark VAR with $Z_{t}^{\prime}=\left[\varpi_{t}^{i \prime}, \mathbf{x}_{2 t}^{\prime}\right]$, where $\mathbf{x}_{2 t}=\left[r p d_{t}\right.$, spread $_{t}, x b r_{t}, x r_{t}$, realr_3$\left.m_{t}\right]$. Thus, the variable of interest, in a recursive fashion is $\log$ difference in securitization, i.e. $d A B S$ or $d M B S$ and the variables in $\mathbf{x}_{2 t}$ are respectively, $\log$ of dividend-price ratio $(r p d)$, term spreads (spread), excess bond returns over two years horizon $(x b r)$, excess market returns $(x r)$, and short term real rates $($ realr_3m).

Figure 3: Impulse Responses - Parsimonious Model
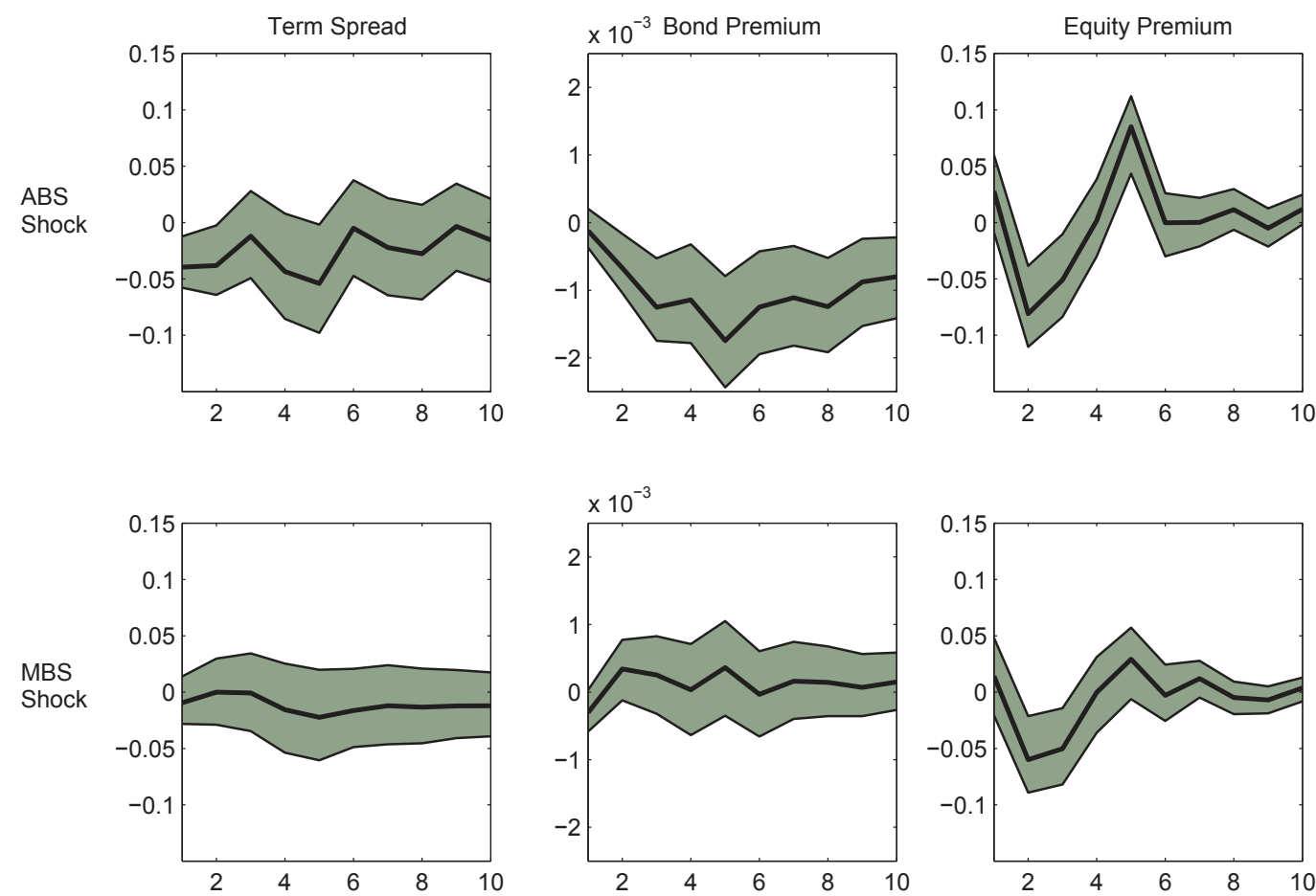

Figure 3 displays the impulse responses with respect to a shock to variations in different types of securitization. The top panels show responses to a shock in changes in $A B S$. We see that term spreads decline significantly. Excess bond (2Y) returns show a significant decline that lasts nearly a year. Excess equity market returns do not respond significantly instantly but suffer a sizeable and significant decline for the next quarter, rebounding quickly after that. Although we only depict the one standard deviation confidence bounds,

\footnotetext{
${ }^{8}$ Although inference is problematic due to shortage of post-crisis data, in one of our robustness exercises we use data after 2008 checking whether the link between securitization and asset prices remain unchanged, see discussion in the next section and Appendix for results.
} 
the cumulative effect of the $A B S$ on bond premium after 5 periods and on the equity premium after 2 periods (their respective peak effects) are both significant at $5 \%$ confidence level. The impulse responses show the effect of changes in securitization volume when all the interactions amongst the asset price variables are considered. We also run predictive return regressions ${ }^{9}$ that include variations in asset backed securitisation among return predictors similar to Adrian Moench and Shin (2010). Lags of asset backed securitization negatively affect term spreads, bond and equity premia. Results show that the direct effect of the changes in securitization (its second lag) on bond and equity premium are significant at $10 \%$ and $5 \%$ confidence level, respectively (see Appendix for the regression output results).

Our results indicate that the link between the variations in the volume of securitization and asset prices is not only statistically significant but also economically significant. A monthly increase of 5 billion USD in the volume of ABS issued in the market (the average monthly volume of ABS issuance from 1993 till 2007 was 36 billion USD, although during 2003-2007 this average was around 75 billion USD) leads to a 5 basis point movement in bond premium after 5 periods, which implies a $10 \%$ movement in bond premium relative to its sample mean, and a 272 basis point decrease in equity premium after 2 periods, which implies a $35 \%$ movement in excess return relative to its sample mean. In order to further analyse the dynamic relationship between securitization and asset prices we also inspect the forecast error variance decompositions (FEV). We observe that by the twelfth month about $7.5 \%$ of variations in excess bond returns is attributable to shocks to variations in $A B S$, about $20 \%$ of variations are attributable to term spread shocks and nearly $70 \%$ of variations are attributable to its own (excess bond returns) shocks. FEV analysis in the case of excess equity market returns also shows a similar contribution of $d A B S$. Over a twelve month horizon, approximately $46 \%$ of forecast error variance in excess market returns are attributable to shocks to dividend-price ratio, whereas $6.2 \%$ of forecast error variance of excess returns are attributable to shocks to variations in $A B S$. As is well known, excess market returns exhibit much less persistence, thus only $39 \%$ of its forecast error variance are attributable to its own shocks. Finally, VAR based excess market returns predictive estimation that includes $d A B S$ increases its in-sample-fit (as measured by the adjusted R-squared) from 2 to 4 points as compared with the VAR specification without the inclusion of $d A B S$.

\footnotetext{
${ }^{9}$ We estimate $R x_{t+1}^{i}=\alpha_{i}+\beta_{i}{ }^{2} * Z_{t}+\varepsilon_{t+1}^{i}$, where $R x_{t+1}^{i}$ consists of excess returns on term structure, bonds and equities and defined as $R x_{t+1}^{i}=\left[\right.$ spread $\left._{t+1}, x b r_{t+1}, x r_{t+1}\right]$ and $Z_{t}$ are the vector of return predictor variables with four lags with dividend price ratio and 3-months real interest rate, lags on the excess returns next to variations in asset backed securitization. We define $Z_{t}=\left[r p d_{t}, r e a l r \_3 m_{t}, d A B S_{t}, R x_{t}^{i}\right]$.
} 
The bottom panels exhibit responses to a shock to variations in mortgage backed securitization. We observe that, initially, spreads decline as in the $A B S$ case but the movement is statistically insignificant. Excess bond returns response to the shock is initially a decline, however it rebounds quickly and becomes insignificant. Finally excess equity market returns response to mortgage backed securitization is similar to its response to the asset backed securitization, i.e. no initial response followed by a stronger and significant decline in excess returns. Overall, we find that the response to a $M B S$ shock is much less pronounced compared to the responses to variations in asset backed securitization. When investigating the FEV, we note that the contributions of shocks to variations in $M B S$ to explain forecast error variance of excess bond returns is negligible and around $2 \%$ for market returns.

We also run the VAR with the aggregate measure of securitization, $d A L L$. Given that the volume of securitization in the mortgage market $(M B S)$ is normally greater than that of $A B S$, the impulse responses (not reported here) are closer to the one observed for $M B S$ than for $A B S$. Overall securitization has a stronger and more significant impact on equity premium than on bond premium. The FEV for excess bond returns suggests that the role of shocks to aggregate securitization in explaining the forecast error variations in excess bond and market returns are negligible. In the case of excess market returns, the role of total securitization is more pronounced in explaining the forecast error variance. By the twelfth month about $10 \%$ of forecast error variance in excess market returns is attributable to shocks to variations in aggregate securitization. Finally, VAR based excess market returns predictive estimation that includes $d A L L s$ increases the in-sample-fit (as measured by the adjusted R-squared) from $2 \%$ to $7 \%$ as compared with the VAR specification without $d A L L s .{ }^{10}$

We perform a series of robustness tests using the parsimonious model, focusing only on the estimation using the variation in the volume of ABS. Details are presented in the appendix. Firstly, we verify whether the impact of securitization on asset prices is driven by the remarkable increase in the volume of deals during the 2003-2007 period, when many new financial instruments were introduced. We restrict the data set to the period 1993 - 2002 and find that the negative impact of innovations to securitization volumes on bond and equity premium remain unchanged. However, securitization shocks contribute relatively less in explaining FEV in excess bond and market returns for this sample period and the size movement in equity premium after an ABS shock is also smaller, reducing to around 150 basis point for a 5 billion monthly increase in ABS, indicating that the link between securitization and asset prices become more relevant during the 2003-2007 period. We also formally assess the stability of the coefficients in our linear specifications. We use the Quandt likelihood ratio (QLR) statistic (in Wald form) and the Andrews-Ploberger

\footnotetext{
${ }^{10}$ All these results are robust to measures of excess bond returns up to five years horizon.
} 
exponential average Wald statistic to assess parameter stability. Our test results suggest that there is no evidence of parameter instability for the period 1993-2007. ${ }^{11}$

Secondly, we use data from January 2009 until October 2013, effectively estimating the period after crisis as a new regime. ${ }^{12}$ Although inference is impaired by the lack of degrees of freedom, we find a similar pattern of response to both bond and equity premia, with a downward movement of bond premium, reaching its lowest level 5 periods after the securitization shock and equity premium moving down after a few periods and rebounding quickly after that. Variance decomposition analysis also paints a similar picture, with securitization shocks contributing to explaining around $6 \%$ of forecast error variance in excess bond returns and around $4.5 \%$ of FEV in excess market returns. Thus, the results indicate that the link between securitization and risk premia across other asset classes has not been substantially altered by the recent crisis, although the monthly volume of deals return to the level observed in the early 2000's.

Thirdly, we focus on the identification assumption by altering the ordering of the variables in the VAR. We set $\mathbf{x}_{2 t}=\emptyset$ and $\mathbf{x}_{1 t}=\left[r p d_{t}\right.$, spread $\left.d_{t}, x b r_{t}, x r_{t}, r e a l r_{-} 3 m_{t}\right]$, thus securitization can only affect asset prices with a lag, but is affected by the other variables contemporaneously. The negative effect of securitization on bond and equity premia are qualitatively unchanged. We also note that shocks to equity and bond premia ${ }^{13}$ do not lead to lower volume of securitization (in fact if anything securitization tends to initially increase after these shocks), thus reverse causality does not seem to hold.

\subsection{Estimation Results - Augmented model}

The results of the parsimonious model of asset return dynamics indicate there is a role for variations to the volume of asset backed securitization in explaining the fluctuations in excess bond and excess market returns. Mortgage backed securitization does not appear to be linked to excess bond returns, although it has significant effects on the equity premium (thus variation in the total volume of securitization explains a significant part of variations in excess market returns). In order to increase our understanding of the added value of looking at the securitization markets to explain risk premia, and assess the robustness of our results, we augment the benchmark model in several directions, particularly focusing on the potential effects of omitted variables.

We subdivide the vector $\mathbf{x}_{2 t}=\left[\mathbf{x}_{2 a t}, \mathbf{x}_{2 b t}\right]$, such that $\mathbf{x}_{2 b t}=\left[\operatorname{rpd}_{t}\right.$, spread $_{t}, x b r_{t}$, $x r_{t}$, realr_3$\left.m_{t}\right]$ contains all the variables included into the benchmark model and $\mathbf{x}_{2 a t}$

\footnotetext{
${ }^{11}$ For details see Andrews (1993), Andrews and Ploberger (1994) and Hansen (2000). Andrews (1993) recommends $\mathrm{t} 1=.15$ and $\mathrm{t} 2=.85$ trimming for the sup-Wald test and for the exponential test, Andrews and Ploberger (1994) recommend $\mathrm{t} 1=.02$ and $\mathrm{t} 2=.98$ trimming. Results are available upon request. We are grateful to Bruce Hansen for providing the matlab code for these tests.

${ }^{12}$ Note that we need one year ahead data to calculate bond premia.

${ }^{13}$ In order to analyse the effect of, for instance, a shock of bond premium, we set $\mathbf{x}_{1 t}=x b r_{t}$ and the remaining variables as part of $\mathbf{x}_{2 t}$, thus bond premium can affect securitization contemporaneously, but the VAR remain as close as possible to the benchmark case. We do the same for spread and excess market returns.
} 
represents additional controls. That way, all controls, together with the securitization can have a contemporaneous effect on asset returns. We now explain each control and the rationale for including them.

It is possible that including of measures of securitization may be serving as instruments for changes in some aggregate risk perception criteria. In order to try and correct for possible biases due to this omission, we incorporate a market volatility measure and set $\mathbf{x}_{2 a t}=v i x_{t}$. The CBOE Volatility Index (vix) captures the investor sentiment and market volatility embedded in the near-term volatility conveyed by S\&P 500 market index option prices as provided by Bloomberg.

Securitization may also be related to future economic performance, as perceived by market participants. In order to account for that we include a measure of consumer expectation about future economic conditions: $E 5 Y$ index is derived from a five years forward looking question on confidence from the Michigan Index of Consumer Expectations (see Barsky and Sims (2011) and Aksoy and Basso (2014) for different applications of the relation between $E 5 Y$ and future economic activity).

Of course, securitization practices may not be directly linked to general economic performance but could be linked to positive news on firm performance that increase credit and equity payoff outlook. Thus, we firstly incorporate the expected earnings-per-share (deps), which is calculated by using the twelve months forward weighted average expected earnings per share based on S\&P 500 composite as reported by I/B/E/S. Secondly, we include a control for aggregate credit spread level using the credit spread index proposed by Gilchrist and Zakrajsek (2012), setting $\mathbf{x}_{2 a t}=g z_{t}$. Thirdly, we control for the growth rate of the volume of corporate bond issuance in the U.S. setting $\mathbf{x}_{2 a t}=$ bond $_{t}{ }^{14}$

Cochrane and Piazzesi (2005) have shown that the five year government bond forward rate is a useful predictor of the excess returns on two year bonds when we abandon the expectations hypothesis. Their explanation is based on the consumption Euler condition. When bond prices are determined by the expected relative marginal utilities divided by inflation, a conditionally heteroscedastic discount factor will generate time varying bond risk premium. Therefore, if financial intermediaries securitization decision is unrelated to the consumption Euler condition, we should see additional information content in variations in securitization next to Cochrane-Piazessi factor $(\mathrm{CP})$; so we set alternatively $\mathbf{x}_{2 a t}=C P_{t}$.

Finally, securitization volumes may be relevant for asset prices since they may be associated with changes in the foreign demand for U.S. securities prior to the crisis (global saving glut hypothesis). In order to account for independent variations in asset prices coming from this channel, we include monthly estimates of foreign holdings of U.S. se-

\footnotetext{
${ }^{14}$ Data on bond issuance is also collected from Dealogic.
} 
curities as provided by Bertaut and Tryon (2007). ${ }^{15}$ We control for all security types, that is Treasury bonds $\left(\mathbf{x}_{2 a t}=\right.$ treas $\left._{t}\right)$, agency bonds $\left(\mathbf{x}_{2 a t}=\right.$ agcyt $)$, corporate bonds $\left(\mathbf{x}_{2 a t}=\operatorname{corp}_{t}\right)$, equities $\left.\left(\mathbf{x}_{2 a t}=s t k_{t}\right)\right)$ and an aggregate measure $\left(\mathbf{x}_{2 a t}=\right.$ tot $\left._{t}\right)$.

Figure 4 displays the corresponding impulse responses that include one of the additional controls (excluding foreign asset demand) at a time when $d A B S$ and when $d M B S$ are used as the securitization measure, respectively. Figure 17 in the appendix shows the effects of foreign demand for U.S. assets. Inspecting these figures suggests that impulse responses remain broadly the same after including different controls. Hence, we conclude that a shock to changes in asset backed securitization leads to a decline in term premium, equity and bond premium, while there is no significant impact of a shock to mortgage backed securitization on excess bond returns and a negative but a relatively smaller effect on excess returns on equity.

Figure 4: Augmented Models - Results
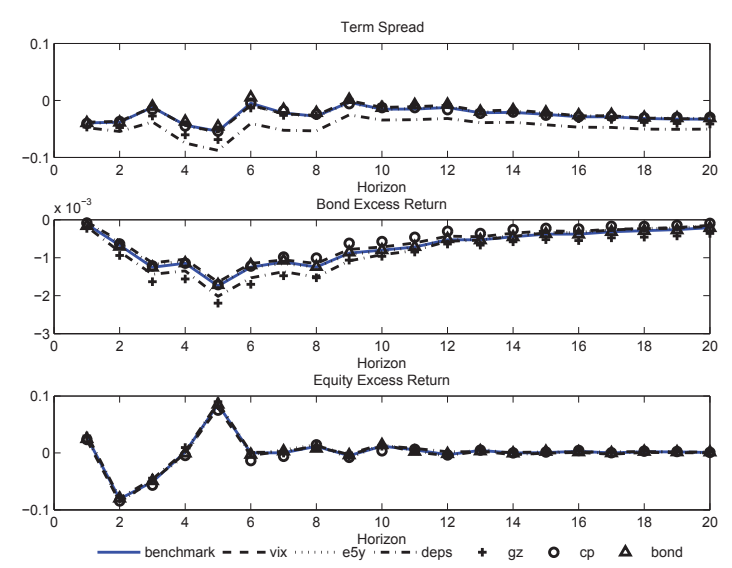
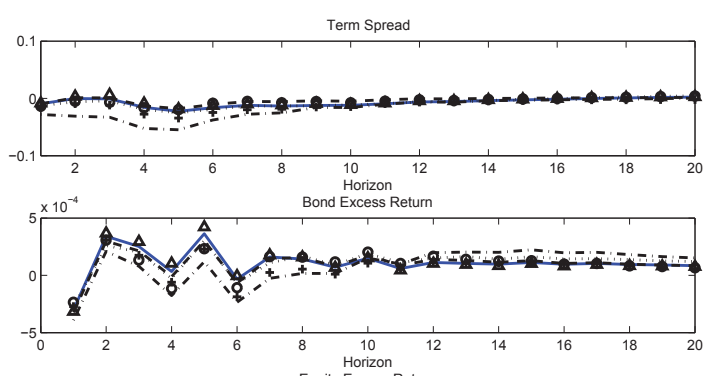

Equity Excess Return

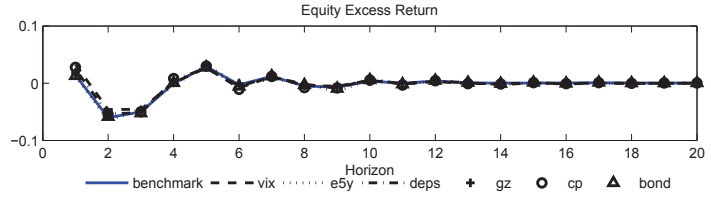

(a) Impulse Response to Asset-backed Securities

(b) Impulse Response to Mortgage-backed Securities

Inclusion of the financial markets volatility as a proxy for risk perceptions (vix) changes the profile of FEV in the case of excess market (equity) returns. When the VAR includes $d A B S$ by the twelfth month about $5.8 \%$ of variations in excess market returns are attributable to shocks to variations in $A B S$, about $42 \%$ of variations are attributable to shocks to vix, about $20 \%$ of forecast error variance in excess market returns are attributable to shocks to dividend-price ratio, whereas $23 \%$ of forecast error variance of excess returns are attributable to its own shocks. In other words, vix is relevant in explaining variations in

\footnotetext{
${ }^{15}$ Essentially, Bertaut and Tryon (2007) data consists of cross-border securities data collected by the Treasury International Capital (TIC) system. Foreign holdings of U.S. securities are measured in the comprehensive surveys of U.S. liabilities to foreigners. These data are available by country of holder, by security type (Treasury bonds, agency bonds, corporate bonds, and equities), and by type of holder (official or private). They combine these periodic survey data with monthly transactions data on crossborder purchases and sales of U.S. Treasury, agency, corporate bonds, U.S. equities, and foreign stocks and bonds (the TIC S data). Further data details are available in Bertaut and Tryon (2007).
} 
the excess market returns, but crucially, the contribution of the volume of securitization remains largely unchanged. A similar picture arises in the case of the inclusion of vix in the VAR with $d M B S$. In the case of VAR estimation with $d A L L s$, by the twelfth month, about $9 \%$ of $\mathrm{FEV}$ in excess market returns are attributable to shocks to $d A L L s, 43 \%$ to shocks to vix, $19 \%$ to shocks to price-dividend ratio and about $22 \%$ to shocks to excess market returns.

Second, while the $C P$ factor appears to be important for explaining the FEV in bond excess returns, controlling for it does not affect the shape of the impulse responses nor the FEV contribution of ABS shocks. By the twelfth month, the shocks to $d A B S$ account for about $6 \%$ of $\mathrm{FEV}$ decompositions in bond excess returns while the $\mathrm{CP}$ factor account for nearly $71 \%$ of variations.

Finally, controlling for total international demand for US financial assets appears to be important in explaining the FEV in equity returns, however, in line with the results with other controls, it does not affect affect the shape of impulse responses and the FEV contribution of ABS shocks.

The empirical results, therefore, indicate that securitization impacts negatively, both, the bond and the equity premium. Moreover, this explanatory power is not related to the potential link between the changes in the volume of transactions in the securitization market with the degree of risk perception/aversion of agents, intertemporal consumption Euler conditions, or with the general economic or credit and equity returns outlook. As a result, the channel through which this effect occurs may be more directly related to the functioning of financial intermediation when the originate to distribute mode of operation is more heavily employed.

Given that our results are stronger when the volume of asset-backed securities is used instead of the one of mortgage backed securities, one must look at shadow banks and securities and brokers dealers, which are more active in that niche of the market relative to traditional commercial banks. Furthermore, shadow banks and broker dealers normally hold a more diverse portfolio of assets that are not only concentrated on credit products but also contain equity and fixed income products, making the potential portfolio effects of the high activity in securitization markets more likely to be observed.

Adrian, Etula, and Muir (2014) and Adrian, Moench, and Shin (2010) look at the link between the growth rate of asset holdings of securities and broker dealers and various asset price measures, stressing the importance of financial intermediation and leverage in determining asset prices. Moreover, Danielsson, Shin, and Zigrand (2012) shows that leverage may be linked to re-valuation of bank capital. The balance sheet data of financial entities at the FED however is only available at a quarterly frequency. We thus run three sets of estimation of a quarterly frequency VAR (with 1 lag). The first includes the same variables as in the benchmark case. The second includes the growth rate of securities and brokers dealers asset holdings as an additional control variable and finally we control for 
variations in bank capital (as measured by the difference between the assets and liabilities of financial business using Flow of Funds data).

Results are presented in the Appendix. From the first estimation we observe that a securitization shock leads to lower equity premia and term spreads, although the effect on bond premium is positive but insignificant. When securities and brokers dealers' assets are included, the effect of securitization on risk premia are quantitatively the same and, as expected, we also observe that asset holdings respond positively to a securitization shock. Finally, when bank capital is included, the effects on term and equity premia remain the same while bond excess return are negative but still statistically insignificant. Note that an increase in secutitization volume does not systematically affect bank capital, but it affects total assets, therefore it only affects leverage.

We believe both our and Adrian, Etula, and Muir's (2014) and Adrian, Moench, and Shin's (2010) results are complementary, pointing to the importance of financial intermediation in explaining asset prices. By focusing on the volume of securitization, we highlight the potential mechanism through which this link occurs. Consequently, in order to increase our understanding of the potential channels through which securitization and financial intermediation activity affects asset prices we build a model of financial intermediation where securitization is used as a form of funding by a financial entity (bank) who holds a diverse portfolio of assets that include credit, government bonds and equity. We turn to that next.

\section{Model}

In order to provide a rationale for the empirical results presented above, we build a partial equilibrium model that focuses particularly on the portfolio choice of banks when securitization of credit assets held on the balance sheet is feasible. As such, banks make two key decisions: the securitization decision, which entails the creation of the securitization market by designing and selling synthetic securities, and the portfolio decision of which assets to hold on their balance sheet.

Initially, there are three assets available for the bank to invest in, credit assets (loans), denoted $Y_{i}$ for $i \in[1, n]$, government bonds $(B)$, and equity $(E)$. Banks will select a portfolio of assets to maximize expected returns (profit) facing two constraints: $(i)$ a cash constraint, as asset purchases must be funded by internal funds (capital) and external funds, which comprise of direct bank borrowing and potential resources prevenient from the securitization market and $(i i)$ a risk constraint, such that banks care about risk. We assume bank capital is constant and is not affected by the securitization activity, as suggested by our empirical evidence.

A fourth asset, denoted $F$, will be created by the bank. We assume the bank creates a Special Purpose Vehicle (henceforth, SPV) which will serve as the agent commerciali- 
zing this asset to final investors. Banks are willing to securitize assets since they have a preference for liquidity ${ }^{16}$ (denoted by $\delta$ ), which is passed on to the SPV. This assumption ensures securitization is a cheaper form of funding relative to direct borrowing. The payoff of $F$ will be a function of the performance of the basket of credit assets $\left[Y_{i}\right]_{i=1}^{n}$, depending on the security design. We assume banks receive information about the payoff structure of credit assets $\left[Y_{i}\right]_{i=1}^{n}$ that is not available to the market at large, hence, the key component influencing the securitization market will be the existence of this information asymmetry.

In order to simplify the exposition and its solution, we divide the model into four stages. In the first stage the bank sets up the SPV, selecting the design of security $F$. During stage 2 the bank receives private information not available to the market at large and selects its portfolio composition. At stage 3 all assets are transacted and in the final stage uncertainty is revealed and assets pay-out. Figure 5 shows the timeline of the model.

Figure 5: Model Timeline

\begin{tabular}{llll|} 
& \multicolumn{1}{c}{2} & 3 & \\
\hline & & & \\
Bank sets up the SPV & Payoff Information $(X)$ & Assets are transacted. & Assets pay-out \\
Selects the design of & revealed. Bank selects & SPV sells a fraction $q$ of & Bank's retained earnings \\
synthetic security $(F)$ & assets $\left\{\left[Y_{i}\right]_{i=1}^{n}, B, E\right\}$, & synthetic securities, and & are determined. \\
given preference & funding $\Upsilon$. Security $F$ & transfers cash to Bank. & \\
for cash $\delta$. & is created at SPV. &
\end{tabular}

\subsection{Securitization Decision}

The securitization decision involves the design of the synthetic security and the setting up of the SPV. Based on that the equilibrium in the securitization market is obtained, allowing the quantity of asset $F$ that is transacted and the price to be determined. These variables will then be used in the portfolio decision to be explained next. Hence, the key assumption is that the securitization and portfolio decisions can be solved independently. This is accomplished by assuming that the SPV only cares about the liquidity generated from the securitization market and that the equilibrium in this market is independent from the portfolio allocation (we relax the second assumption in section 3.4). The securitization part of the model follows DeMarzo and Duffie (1999) and DeMarzo (2005) closely. In order to determine the security design and the market equilibrium we introduce a number of assumptions regarding the credit assets.

\footnotetext{
${ }^{16}$ Liquidity generation is not the only reason for securitizing assets. This may occur due to the desire to transfers risk. The risk effect will also be explored in our model. For a model where securitization does not transfer risk but is used to reduce capital requirements see Acharya, Schnabl, and Suarez (2013).
} 
Each asset $i$ has a final payoff of $Y_{i}=X_{i}+Z_{i}$. The component $X_{i}$ represents the bank's private information about the payoff of the credit asset that is not available to other investors. $Z_{i}$ represents the remaining risk the bank faces. We assume $Z_{i}$ can be divided into two components, an idiosyncratic part and an aggregate credit market component, thus $Z_{i}=\epsilon_{i}+\eta$. Let $Y^{n} \equiv \sum_{i=1}^{n} Y_{i}$ denote the cumulative payoff of credit assets and $Y \equiv\left(Y_{1}, \ldots, Y_{n}\right)$ the vector of assets. Same definitions hold for $X, X^{n}, Z$, and $Z^{n}$. Finally, let $X_{-i} \equiv\left(X_{1}, \ldots, X_{i-1}, X_{i+1}, \ldots, X_{n}\right)$.

We then make the following assumptions

- A1. $E\left[Z_{i} \mid X\right]=0$ or $E\left[Y_{i} \mid X\right]=X_{i}$.

- A2. Given any $X_{-i}$, the conditional support of $X_{i}$ is a closed interval and has greatest lower bound $X_{i 0}>0$.

- A3. $\epsilon_{i}$ and $\eta$ are independent of $X$ and have log-concave density functions.

Assumptions 1 and 2 guarantee that $X$ comprises all information available on $Y$, that given the information on all other assets, there is still a range of possible information states for asset $i$, and that the lower bound of that range is independent of $X_{-i}$. Finally, Assumption 3 ensures enough regularity on the distribution of shocks to allow for the determination of the security design.

\section{The securitization market and the creation of SPV}

We assume the bank issues synthetic securities $F$ and place them on the balance sheet of an SPV. The key characteristic of the SPV is its preference for transforming these securities in cash, or a liquidity preference. We denote this preference by parameter $\delta .{ }^{17}$ Based on that, the SPV selects the amount $q$ of synthetic securities to sell. Let $P_{F}(q)$ denote the price of the synthetic security $F$ when $q$ units are sold, or the demand schedule for security $F$. Then the SPV selects $q$ equals to

$$
\arg \max _{q \in[0,1]} q P_{F}(q)+\delta(1-q) E[F \mid X]=\arg \max _{q \in[0,1]} q\left(P_{F}(q)-\delta E[F \mid X]\right)
$$

Thus, the preference for liquidity implies that assets not sold are discounted relative to the cash gains from transacted synthetic securities. Therefore, the key characteristic of the SPV is its desire to sell as much securities $F$ as possible, since it prefers holding cash (and transferring it back to the bank) than holding $F$ on its balance sheet (although its price might be equal to its expected value). The main obstacle for the SPV or for the functioning of the securitization market is the existence of information asymmetries between the final investor and the SPV. Given its preference for liquidity, if the security

\footnotetext{
${ }^{17}$ We later link that to the implicit value of the cash constraint of the bank portfolio problem.
} 
$F$ is priced according to its value based on all information available, let that price be $f=E[F \mid X]$, then the SPV would want to publicly offer all stock of synthetic securities or set $q=1$. Would final investors be willing to buy all the stock of synthetic securities? Final investors do not have the same information set as the bank and will be trying to determine the appropriate price. Assume he/she bids the lowest possible price (linked to the lower bound of $X$, denoted $f_{0}=E\left[F \mid X=X_{0}\right]$ ). On the on hand, if the SPV/bank receives a signal $X>X_{0}$, the value of the security is higher than the price bid by the final investor and thus the SPV may not be willing to sell all the stock of securities $F$, offering only a lower proportion to the market $(q<1)$, thus indicating to investors that the security is better than expected and its price should be greater than $f_{0}$. On the other hand, if the SPV received the worst possible signal $\left(X=X_{0}\right)$, it will sell all securities confirming the final investor's initial expectation. Hence, given a bid price of $P_{F}$, the public offer of the SPV $(q)$ will convey information about the bank's private information on the conditional payoff of the security. In summary, the SPV security retention (offering $q<1$ ) is a credible signal (of higher $X$ ) since retention is costly due to its preference for liquidity. The market equilibrium $\left(P_{F}, q\right)$ is thus the equilibrium of a signalling game in which uninformed investors compete for purchases of the security being offered by the SPV in a Walrasian market setting.

DeMarzo and Duffie (1999) provide the following characterization of this equilibrium. Under assumptions $A 1$ - A2,

$$
q=\left(f / f_{0}\right)^{-1 /(1-\delta)} \text { and } P_{F}=f_{0}(q)^{\delta-1}=f
$$

is a unique separating equilibrium. The SPV payoff function will be $\Pi^{S P V}\left(f, f_{0}\right)=$ $q\left(P_{F}(q)-\delta E[F \mid X]\right)=f_{0}(1-\delta)\left(f / f_{0}\right)^{-\delta /(1-\delta)}$, where $f=E[F \mid X]$, and $f_{0}=E[F \mid X=$ $X_{0}$ ]. The equilibrium is obtained by solving (2), conditional on $P_{F}=f$, and imposing the boundary condition that $P_{F}(1)=f_{0}$.

\section{Optimal Design of F}

Having obtained the characterization of the equilibrium in the securitization market we can now solve backwards to determine the security design (stage 1 in the model ${ }^{18}$ ). Given the timeline of the model the synthetic security design is done before $X$ is revealed to the bank. Hence, the optimal design problem is given by $\max _{F(.)} E\left[\Pi^{S P V}\left(f, f_{0}\right)\right]$. DeMarzo and Duffie (1999) and DeMarzo (2005) show that under assumptions $A 1$ - A3 the optimal monotone security design is a standard debt contract. ${ }^{19}$ That is $F^{*}(Y)=\min \left(d, Y^{n}\right)$

\footnotetext{
${ }^{18}$ Note that we do not need to determine the decision in stage 2 since the optimal design and the portfolio decision are independent.

${ }^{19}$ We are assuming the bank will find it optimal to pool all credit assets together and set a debt contract dependent on $Y^{n}$, instead of issuing a security $F$ for each asset $Y_{i}$. As DeMarzo (2005) shows, for a large number of securities in the pool, when the variance of the idiosyncratic risk $\epsilon_{i}$ is big enough, the risk diversification effect is stronger than the information destruction effect. In this scenario, pooling and tranching delivers higher payoff than tranching alone.
} 
for a constant $d$. The intuition is simple. The bank/SPV would like to maximize the volume of securitized assets, but due to the information asymmetry, is forced to retain some synthetic assets in the portfolio when the signal is good and information asymmetry is high. Hence, it is optimal for the SPV to select a security that is as payoff insensitive as possible for the range of signals where asymmetry is at its highest. Standard debt has this property since $f$ does not change significantly as $X$ increases in the range $X \gg d$. That way, the bank problem is

$$
\max _{d} E\left[\Pi^{S P V}\left(f^{d}, f_{0}^{d}\right)\right], \text { where } f^{d}=E\left[\min \left(d, Y^{n}\right) \mid X\right] .
$$

In order to provide further characterization on the debt contract, $P_{F}$ and $q$, we assume that $\eta \sim N\left(0, \sigma^{2}\right)$ (recall that $\eta$ is the aggregate credit shock affecting all credit assets) and $X^{n}$ is uniformly distributed between $X_{0}=\sum_{i} x_{i 0}$ and $X_{1}=\sum_{i} x_{i 1}$. As we increase the number of securities $n$, the value of $f$ becomes

$$
\begin{aligned}
f_{n}^{d}= & E\left[\min \left(d, X^{n}+(1 / n) \sum \epsilon_{i}+\eta\right) \mid X\right] \rightarrow E\left[\min \left(d, X^{n}+\eta\right) \mid X\right]=f^{d} \\
f^{d}= & \int_{-\infty}^{\left(d-X^{n}\right)}\left(X^{n}+\eta\right) f(\eta) d \eta+\int_{\left(d-X^{n}\right)}^{\infty} d f(\eta) d \eta \\
& \text { where } f(\eta) \text { is the density function of } \eta \\
f^{d}= & X^{n} \Phi\left(\frac{d-X^{n}}{\sigma}\right)+d\left(1-\Phi\left(\frac{d-X^{n}}{\sigma}\right)\right)-\sigma \phi\left(\frac{d-X^{n}}{\sigma}\right)
\end{aligned}
$$

where $\Phi(\cdot)$ and $\phi(\cdot)$ are the standard normal cumulative and density functions

Also note that $f_{0}^{d}=X_{0} \Phi\left(\frac{d-X_{0}}{\sigma}\right)+d\left(1-\Phi\left(\frac{d-X_{0}}{\sigma}\right)\right)-\sigma \phi\left(\frac{d-X_{0}}{\sigma}\right)$. The aggregate shock $\eta$, which is not diversified away as the basket of credit is constructed can also be understood as the correlation risk amongst assets $Y_{i}$, for $i \in[1, n]$, within the basket.

Based on the solution for $f^{d}$ and $f_{0}^{d}, d^{*}$ is given by

$$
d^{*}=\arg \max \int_{X_{0}}^{X_{1}}(1-\delta)\left(f_{0}^{d}\right)^{1 /(1-\delta)}\left(f^{d}\right)^{-\delta /(1-\delta)} \frac{1}{\left(X_{1}-X_{0}\right)} d X
$$

We are not able to obtain an analytical solution to this integral and thus offer a description of the main trade-off involved in the selection of $d^{*}$. Due to the presence of information asymmetry the SPV is forced to retain a fraction $(1-q)$ of synthetic securities. That is costly since it prevents the SPV from maximizing liquidity creation. Hence, one of the drivers behind the selection of $d^{*}$ is to minimize the information sensitivity of $F$. Figure 6 shows the pay-off of the synthetic security to the final investor for a low value of $d=\tilde{d}$ (left-hand side) and for a high value of $d=\hat{d}<X_{0}$, also depicting the range of possible information $X^{n} \in\left[X_{0}, X_{1}\right]$. On the one hand, when $d$ is small, the probability that $Y^{n}$ (payoff of credit) is such that the payoff of final investors is negative (region $A$ ) is quite small (far away from range $\left[X_{0}, X_{1}\right]$ ) and the actual loss is also small. On the other hand, when $d$ is high the probability that $Y^{n}$ is such that the payoff is negative (region $B$ ) is greater (not far from range $\left[X_{0}, X_{1}\right]$ ) and the potential loss more sizeable. Hence, 
for $d=\hat{d}$ it is relevant from the point of view of the final investor to know if $X^{n}=X_{0}$ or $X^{n}=X_{1}$, while when $d=\tilde{d}$ it is not as much. That is, the bank wants to select $d^{*}$ as small as possible to minimize the information sensitivity $F$, maximizing $q$. However, as the bank decreases $d^{*}$, it also decreases $P_{F}\left(d^{*}\right)$ since $d^{*}>P_{F}\left(d^{*}\right)$. As a result, total cash for each unit of synthetic security sold is smaller. Thus, the desire to maximize cash receipts from securitization through the price of security pushes $d^{*}$ up. Optimal $d^{*}$ balances the trade-off between these two effects, maximizing $P_{F}\left(d^{*}\right) q\left(d^{*}\right)$.

Figure 6: Synthetic Security Payoff and Optimal $d$

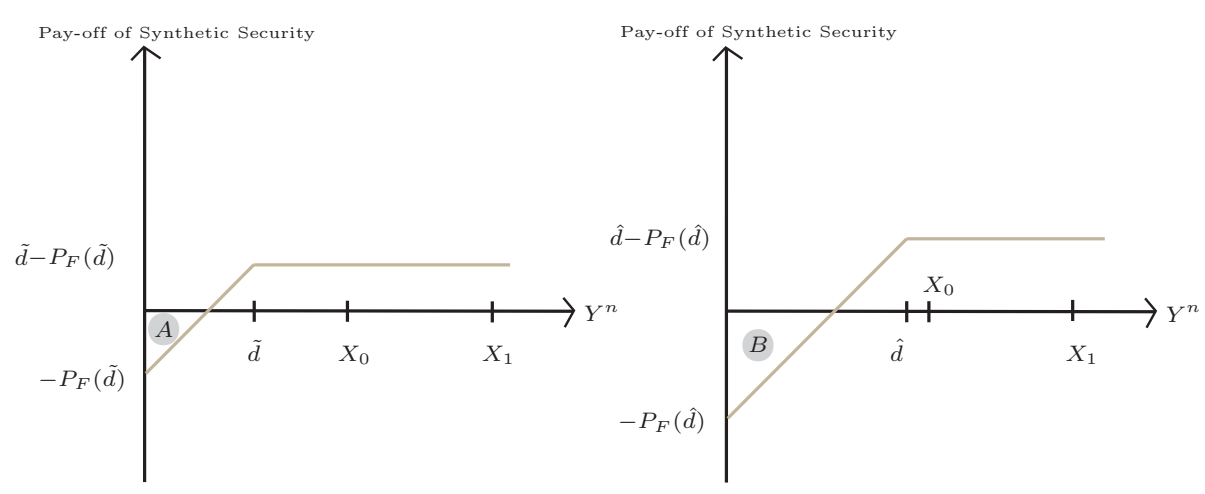

\subsection{Portfolio decision}

Banks select a portfolio of equity, government bonds and credit to maximize expected returns. Banks invest in three main assets: credit assets (loans), denoted $Y_{i}$ for $i \in[1, n]$, government bonds $(B)$, and equity $(E)$. Given the assumptions made on the returns of credit assets $\left[Y_{i}\right]_{i=1}^{n}$, and the fact that banks pool all these assets to design the synthetic security, instead of looking at each asset $i$, we can concentrate directly on the credit basket whose payoff is equal to $Y^{n}$. Let $Q_{y}$ be the quantity of pooled credit assets the banks buy. Recall that due to the diversification of idiosyncratic risks $\left(\epsilon_{i}\right)$, the only source of risk of the basket of credit comes from the aggregate uncertainty $(\eta)$. We assume the price of the basket is given by its expected payoff conditional on the banks information set $P_{y}=E\left[Y^{n} \mid X^{n}\right]$, but assume the bank can extract a credit mark-up (denoted $\mu\left(X^{n}, Q_{y}\right)$ ) while acting as a financial intermediary. Although we do not model that explicitly this could be due to the its informational advantage as in DeMarzo (2005), or because it has some bargaining power over firms/agents that make loans. We assume $\mu\left(X^{n}, Q_{y}\right)$ is a function of $(i)$ the signal $X^{n}$; the greater $X^{n}$ relative to the lower bound $X_{0}$ the greater the bank's information advantage and thus higher the mark-up; and (ii) the quantity 
transacted $Q_{y}$; the greater the bank's demand for credit assets (supply of loans), the lower its mark-up. Thus, for $\mu_{1}, \mu_{2}>0$, we assume

$$
\mu\left(X^{n}, Q_{y}\right)=\bar{\mu}+\mu_{1}\left(X^{n}-X_{0}\right) / X_{0}-\mu_{2} Q_{y} .
$$

Government bonds payoff is given by $V_{B}$. We assume $V_{B} \sim N\left(\varpi_{B}, \sigma_{B}^{2}\right)$. Banks buy $Q_{B}$ units of bonds and pay price $P_{B}$ for each unit. Equity payoff is given by $V_{E}$. We assume $V_{E} \sim N\left(\varpi_{E}, \sigma_{E}^{2}\right)$. Banks buy $Q_{E}$ units of equity and pay price $P_{E}$ for each unit. Banks take prices $P_{E}$ and $P_{B}$ as given while selecting their portfolio composition. Prices are then determined in equilibrium based on market demand schedules $P_{B}\left(Q_{B}\right)$ and $P_{E}\left(Q_{E}\right)$ given by

$$
\begin{gathered}
P_{B}=\alpha_{B}+\beta_{B} Q_{B} \\
P_{E}=\alpha_{E}+\beta_{E} Q_{E} .
\end{gathered}
$$

In order to fund these assets, banks utilize internal funds (capital), denoted by $\Gamma_{0}$, and external funds, which comprise of direct bank borrowing $(\Upsilon)$ and resources prevenient from the securitization market, which, from the results in the previous section, comprise $q P_{F}$ for each unit of pooled credit asset $\left(Q_{y}\right)$. As a result of the separation between the securitization and portfolio decisions, the bank, at this stage, takes $\left(q, P_{F}, f, f_{0},\right)$ as given. The cost of bank borrowing is given by $R_{F}=\bar{R}+\kappa\left(\Upsilon / \Gamma_{0}\right)$. Thus, we assume the cost of external funding increases from a base rate $\bar{R}$ as borrowing increases relative to the amount of bank capital. Bank profits/returns $\left(\Pi^{B}\right)$ are then given by

$$
\begin{aligned}
\Pi^{B} \mid X^{n}= & Q_{y}\left(Y^{n}-P_{y}\right)+\mu\left(X^{n}, Q_{y}\right) Q_{y} \\
& +Q_{B}\left(V_{B}-P_{B}\right)+Q_{E}\left(V_{E}-P_{E}\right)-q Q_{y}\left(F-P_{F}\right)-R_{F} \Upsilon .
\end{aligned}
$$

We assume banks select the portfolio composition $\left(Q_{y}, Q_{B}, Q_{E}, \Upsilon\right)$ to maximize the expected profits $E\left[\Pi^{B} \mid X^{n}\right]$ subject to two constraints. The first asserts that the cost of purchase of assets is equal to the amount of funds, or a cash constraint. That is given by

$$
Q_{y} P_{y}+Q_{B} P_{B}+Q_{E} P_{E} \leqslant \Gamma_{0}+q Q_{y} P_{F}+\Upsilon
$$

The second ensures the bank abides by a limit on risk taking or a risk constraint. ${ }^{20}$ It is common to assume that this constraint takes the form of the first percentile of the distribution of expected returns, or a Value-at-risk constraint. Although widely used in

\footnotetext{
${ }^{20}$ Adrian and Shin (2008) provide a contracting model motivating the use of such constraints.
} 
practice this type of constraint introduces complexity to the portfolio problem. Instead, we assume that the bank faces a limit to the standard deviation of the portfolio returns. If the assets in the portfolio were only credit, bonds and equity, given the assumption on normally distributed payoff, the two constraints (limit on standard deviation and on the percentile of the distribution) are equivalent. When synthetic products are assumed then the two may diverge since asset $F$ 's payoff distribution is not symmetric.

The standard deviation of the portfolio returns is given by

$$
\begin{aligned}
\sigma_{\Pi^{B}} \mid X^{n}= & \left(Q_{y}^{2} \sigma^{2}+Q_{B}^{2} \sigma_{B}^{2}+Q_{E}^{2} \sigma_{E}^{2}+2 Q_{y} Q_{B} \sigma_{y B}+2 Q_{y} Q_{E} \sigma_{y E}+\right. \\
& \left.2 Q_{B} Q_{E} \sigma_{E B}-2 q Q_{y}^{2} \sigma_{F Y}-2 q Q_{y} Q_{B} \sigma_{F B}-2 q Q_{y} Q_{E} \sigma_{F E}+q^{2} Q_{y}^{2} \sigma_{F}^{2}\right)^{1 / 2} .
\end{aligned}
$$

Where $\sigma_{a b}$ is the covariance between the payoff of securities $a$ and $b$, and $\sigma_{F}^{2}$ is the variance of the synthetic security. The risk constraint limits the standard deviation of the bank profits to be smaller or equal to a fraction of the total capital of the bank. This fraction $(\chi)$, denotes the degree of risk aversion of the bank. Thus, the portfolio choice must be such that

$$
\sigma_{\Pi^{B}} \leqslant \chi \Gamma_{0}
$$

Given the security design and the solution for $f^{d}$ we can now determine the variance and covariances that involve the synthetic security $F$. They are (details can be found in the Appendix)

$$
\begin{aligned}
\sigma_{F}^{2} \mid X^{n}= & \left(X^{n}\right)^{2} \Phi\left(\frac{d-X^{n}}{\sigma}\right)-2 X^{n} \sigma \phi\left(\frac{d-X^{n}}{\sigma}\right)-\sigma^{2}\left[\frac{d-X^{n}}{\sigma} \phi\left(\frac{d-X^{n}}{\sigma}\right)-\Phi\left(\frac{d-X^{n}}{\sigma}\right)\right]+d^{2}\left[1-\Phi\left(\frac{d-X^{n}}{\sigma}\right)\right]-\left(f^{d}\right)^{2} \\
\sigma_{F y} \mid X^{n}= & \left(X^{n}\right)^{2} \Phi\left(\frac{d-X^{n}}{\sigma}\right)-2 X^{n} \sigma \phi\left(\frac{d-X^{n}}{\sigma}\right) \\
& -\sigma^{2}\left[\frac{d-X^{n}}{\sigma} \phi\left(\frac{d-X^{n}}{\sigma}\right)-\Phi\left(\frac{d-X^{n}}{\sigma}\right)\right]+d\left[X^{n}\left(1-\Phi\left(\frac{d-X^{n}}{\sigma}\right)\right)+\sigma \phi\left(\frac{d-X^{n}}{\sigma}\right)\right]-f^{d} X^{n} \\
\sigma_{F B} \mid X^{n} \approx & \Phi\left(\frac{d-X^{n}}{\sigma}\right) \sigma_{y B} \\
\sigma_{F E} \mid X^{n} \approx & \Phi\left(\frac{d-X^{n}}{\sigma}\right) \sigma_{y E}
\end{aligned}
$$

The portfolio problem is given by

$$
\max _{\left\{Q_{y}, Q_{B}, Q_{E}, \Upsilon\right\}} E\left[\Pi^{B} \mid X^{n}\right] \quad \text { s.t. } \quad(9) \text { and (10) }
$$

Note that as a solution to this problem is obtained, one can find the shadow value (in term of profits) of an extra unit of cash holding to the bank (lagrange multiplier of the cash constraint, denoted $\lambda_{c}$ ). We can use this multiplier to pin down the value of $\delta$, the bank's liquidity preference, or the discount factor of the SPV. Essentially, we will set $\delta=1-\lambda_{c}$, where $\lambda_{c}$ is obtained when the portfolio decision is solved while setting $q=0$, or without securitization. This way we assess the bank's desire to obtain cash from securitization. 


\subsection{Model Results}

The equilibrium of the model is defined as the vector of asset allocation $\left\{Q_{y}, Q_{B}, Q_{E}\right.$, $\Upsilon, q\}$ and the vector of prices $\left\{\mu, P_{B}, P_{E}, P_{F}, d\right\}$ such that $(i)$ given prices $\left\{Q_{y}, Q_{B}, Q_{E}, \Upsilon\right\}$ solves problem (11); (ii) $\left\{q, P_{F}\right\}$ is a separating equilibrium of the signalling game; (iii) the face value of debt $d$ is given by (4); and (iv) given $\left\{Q_{y}, Q_{B}, Q_{E}\right\}$, prices $\left\{\mu, P_{B}, P_{E}\right\}$ are consistent with the credit spread (mark-up), (5), and the market demand schedules (6) and (7).

Our main interest is to verify the effect of securitization on the portfolio allocation of banks, and through that, its effect on asset risk premia. The bond risk premia in our model can be defined as $B P\left(Q_{B}\right) \equiv E\left[V_{B}\right]-P_{B}$, while the equity risk premia is given by $E P\left(Q_{E}\right) \equiv E\left[V_{E}\right]-P_{E}$. Given that the portfolio decisions and the equilibrium in the securitization market are a function of the information set $X^{n} \in\left[X_{0}, X_{1}\right]$, the equilibrium is obtained for $X^{n}$ within that interval. Note that when $X^{n}=X_{0}$, banks do not have an information advantage over the market, since the existence of the lower bound $X_{0}$ is known. However, as $X^{n}$ increases from $X_{0}$, banks have an advantage in determining the true value of the credit basket, hence, the degree of information asymmetry between final investors and the bank increases. We solve the model for two cases, one where we constrain $q=0$, hence the market of securitization is disregarded (denoted Model No Sec) and one where $q$, the securitization volume, is obtained based on the separating equilibrium described above (denoted Model with Sec).

Due to the non-linearity of the risk constraint and the integral needed to the solved to obtain the face value of debt (see (4)) we can only obtain numerical solutions. The parameters used in the benchmark specification are shown in table $1 .{ }^{21}$ Starting from the return parameters, we set the mean payoff on bonds to be around $5 \%$ and the mean payoff on equity to be that plus $3 \%$. The parameters $\left\{\alpha_{B}, \alpha_{E}\right\}$ are set such that if banks do not buy any bonds or equity the risk premia on each asset are slightly above their mean average in the data used in the empirical section. Parameters $\left\{\beta_{B}, \beta_{E}\right\}$ control the sensitivity of the risk premia to increases in bank asset demand. This is set such that if the bank uses all its capital to buy one asset it offsets most of the premia, ensuring bank portfolios are not concentrated in one asset. We set the credit basket to pay a mark-up slightly greater than the equity premium since credit is the riskier asset. The variance and covariance structure is based on the data for government bond returns, the return on the S\&P500 and the credit spread index (GZ) proposed by Gilchrist and Zakrajsek (2012). Using this data we find that the standard deviation of equity returns is $60 \%$ the standard deviation of credit spreads, while that ratio is $20 \%$ for the case of government bonds. All asset payoffs are found to be negatively correlated as reported in the table. We set $X_{0}$ to be equal to 1.02 and the degree of information asymmetry $m$, given by the different between $X_{0}$ and

\footnotetext{
${ }^{21}$ Although no calibration exercise is done we attempt to select parameters based on the relevant financial market data.
} 
$X_{1}$, is set to 0.2 (two times the standard deviation of the aggregate shock). Finally, we set $\delta$ to be equal to 1 minus the lagrange multiplier obtained from the solution of the bank portfolio when securitization is not performed and limit the standard deviation of the portfolio to be $7 \%$ of the banking capital (under normally distributed returns that would imply limiting the loss under the first percentile (Value-at-risk) to roughly $25 \%$ of bank capital). We perform different sensitivity analysis to most of the parameters described in table 1 to verify the robustness of our predictions, but also as a tool to increase the understanding of the key mechanism behind the impact of securitization on risk premia.

\begin{tabular}{cccccc}
\multicolumn{4}{c}{ Table 1: Parameter Values - Benchmark Model } \\
\hline \hline \multicolumn{5}{c}{ Return } & \multicolumn{3}{c}{ Variance } & \multicolumn{2}{c}{ Bank } \\
$\varpi_{E}$ & $0.03+1 / 0.95$ & $\sigma_{Y}$ & 0.1 & $\delta$ & 0.983 \\
$\varpi_{B}$ & $1 / 0.95$ & $\sigma_{B}$ & 0.02 & $\Gamma_{0}$ & 5 \\
$\alpha_{B}$ & $\varpi_{B}-0.02$ & $\sigma_{E}$ & 0.06 & $\chi$ & 0.07 \\
$\alpha_{E}$ & $\varpi_{B}+0.01$ & $\rho_{E Y}$ & -0.49 & & \\
$\beta_{B}$ & $\frac{1}{\Gamma_{0}} 0.025$ & $\rho_{E B}$ & -0.57 & & \\
$\beta_{E}$ & $\frac{1}{\Gamma_{0}} 0.025$ & $\rho_{B Y}$ & -0.4 & & \\
$\bar{R}$ & 0.01 & & & & \\
$\kappa$ & $\frac{1}{\Gamma_{0}} 0.05$ & Information & & \\
$\mu_{1}$ & 0.01 & $X_{0}$ & 1.02 \\
$\mu_{2}$ & $\frac{1}{\Gamma_{0}} 0.005$ & $m$ & 0.2 & \\
$\bar{\mu}$ & 0.04 & $X_{1}$ & $X_{0}+m$ \\
\hline \hline
\end{tabular}

\subsubsection{Benchmark model}

We start by presenting the results of the benchmark model. Figure 7 shows the difference between the equilibrium of the full model (Model with Sec) and the one obtained by setting $q=0$, or restricting the bank to do no securitization. We report the bond and equity premia, the final credit market spread or mark-up $\left(\mu\left(X^{n}, Q_{y}\right)\right)$, the bank's asset holdings/balance sheet $\left(Q_{y}+Q_{B}+Q_{E}\right)$, the amount of securitization $(q)$ and finally the percentage point change in the ratio of external borrowing and bank capital, measuring the degree of leverage based on direct borrowing. The results are shown for the entire range $X^{n} \in\left[X_{0}, X_{1}\right] .{ }^{22}$ Note that the the degree of information asymmetry in the market is directly related to the difference between $X^{n}$ and the lower bound $X_{0}$, which is known. Hence, we define information asymmetry as the ratio $\left(X^{n}-X_{0}\right) / X_{0}$.

\footnotetext{
${ }^{22}$ We smooth the final solution to correct for potential inaccuracies in the numerical optimization solution, see the Appendix for more details.
} 

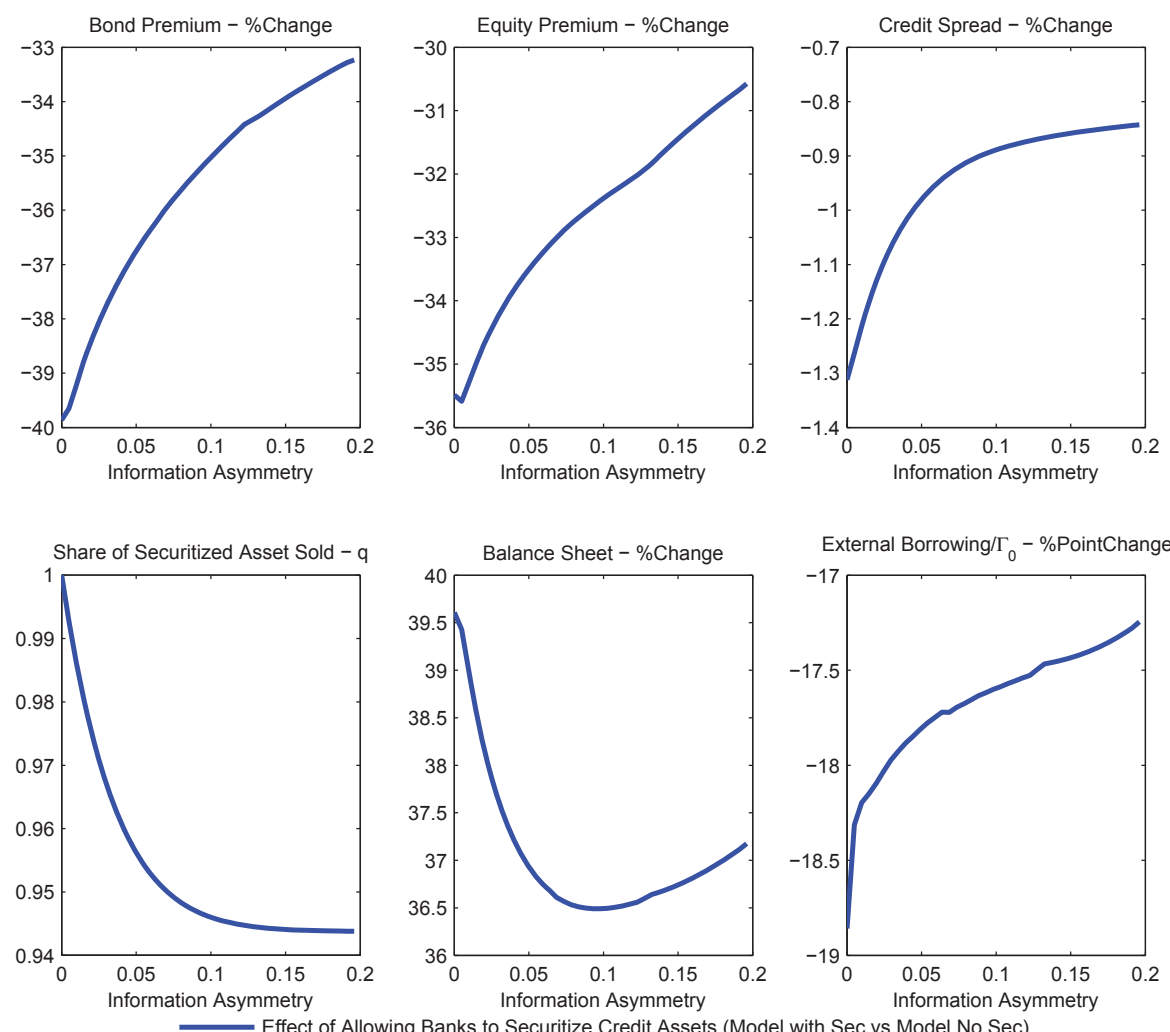

Firstly, allowing for securitization to be conducted implies the bank is able to increase its asset holdings (balance sheet) across all the range of information asymmetries $\left(\left[0,\left(X_{1}-\right.\right.\right.$ $\left.\left.\left.X_{0}\right) / X_{0}\right]\right)$. This increase pushes bond premium, equity premium and credit mark-up down. Second, securitization is at its highest when information asymmetry is at its lowest. The SPV does not need to retain any synthetic security when it does not have an informational advantage relative to final investors. As information asymmetry increases it must retain a greater portion of synthetic assets, not being able to exploit the securitization market as much. As a result, balance sheet expansion generally decreases with more information asymmetry, ${ }^{23}$ and consequently, the equilibrium bond and equity premium respond less. The balance sheet expansion affects all three assets for two main reasons: $(i)$ due to market demand sensitivity concentrating all expansion in one asset reduces the return on that asset relative to the others, and (ii) due to diversification gains banks are able to manage risk exposures more effectively by increasing allocation of all assets. Another interesting feature is the effect of securitization on the liabilities side of the balance sheet. We observe that securitization replaces external borowing as a source of funding, in fact securitization becomes the main source of funding. Leverage based on external borrowing $(\Upsilon)$ decreases significantly relative to the case when securitization is not allowed.

\footnotetext{
${ }^{23}$ The increase observed as $X^{n} \rightarrow X_{1}$ occurs since securitization shares become constant but credit assets are becoming relatively better assets and $P_{F}$ increases with $X^{n}$ and thus the liquidity created for each unit of securitized asset increases.
} 
Hence, the key conclusion of the theoretical model is that although the intrinsic characteristics of the assets (payoff and risk) in the banks portfolio has not changed and the bank's degree of risk aversion (represented by parameter $\chi$ ) has remained the same, we observe that the risk premia required to maintain those assets on the balance sheet decrease substantially as securitization is employed. This confirms the empirical results presented in section 2. We find that an increase in securitization implies a drop in risk premia after controlling for a set of variables that are related to the future payoff of the assets (e.g. dividend/price ratios, earnings-per-share, consumer expectations) or the degree of risk aversion in the market (e. g. vix). The main driver of the volume of securitization is the degree of information asymmetry. Thus, through the portfolio selection of the bank, the degree of information asymmetry in credit markets leads to variation in risk premia.

This portfolio channel is present due to the effect of securitization on the two main constraints the bank face. Firstly, while external funds are costly since direct borrowing must carry an interest rate that is increasing as bank leverage increases, banks are able to acquire funds by creating and selling the synthetic securities that are linked to their balance sheet holdings at significantly lower costs. Thus, securitization relaxes the bank's cash constraint. Secondly, by designing a debt contract as the format of the synthetic security the bank is also decreasing the extent of risk taking in credit markets. To see this compare the payoff of a (naked) credit basket (left panel in Figure 8), the short position on the synthetic security (middle panel in Figure 8) and a portfolio that combines a long position on the basket and a short position on the synthetic security (or the final portfolio of the bank after securitization, depicted in the right panel of Figure 8). The short position on the synthetic security essentially protects the bank against losses when the credit basket payoff $\left(Y^{n}\right)$ is lower than the face value of debt $(d)$. Thus, securitization also relaxes the bank's risk constraint. ${ }^{24}$ As a result, banks find it optimal to increase asset holdings. Since, banks have a preference for diversification both due to the risk constraint and the negative expected gain from overbidding in one single market, banks increase holding of all asset classes. Therefore, securitization of credit implies low risk premia across all asset classes.

In the benchmark model we assume banks select $d$ optimally to maximize the SPV gains from securitization. Given that the key aim is to decrease the effects of information asymmetry and thus reduce SPV retention of synthetic securities, banks set $d^{*}$ quite low (optimal $d$ is 0.81 , significantly lower than $X_{0}=1.02$ ). ${ }^{25}$ As a result, the proportion of

\footnotetext{
${ }^{24}$ Note that securitization affects the left tail of the distribution of returns and thus the fact we use a constraint on the standard deviation instead of a constraint on the first percentile of losses decreases the risk protection provided by securitization. This would be stronger for a standard Value-at-Risk constraint, increasing the effects of securitization on risk premia.

${ }^{25}$ Setting $d$ low is effectively the same as attempting to create AAA (safe) tranches, whose price will then be insensitive to asymmetric information. Increasing $d$, for the same underlying asset, generates lower rated tranches or riskier synthetic securities.
} 
Figure 8: Risk Profile

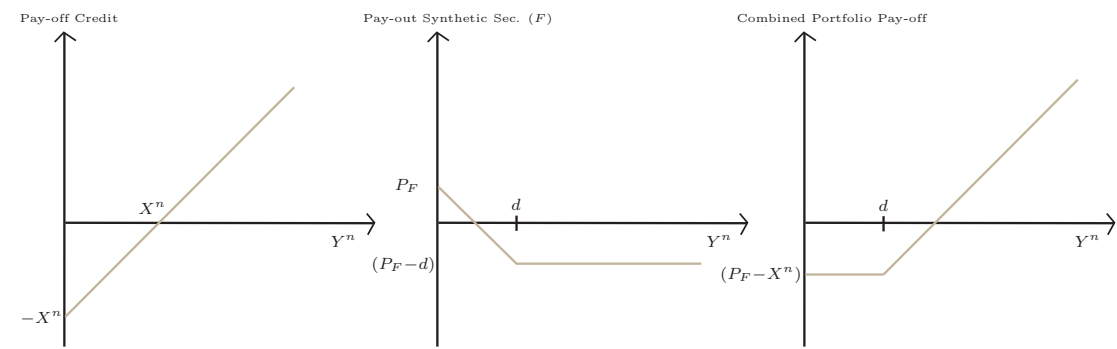

securitized assets traded $(q)$ is greater than 0.94 for all $X^{n}$. However $d^{*}$ also has implications for the degree of risk protection a short position on synthetic securities provide. This protection increases with $d$. We thus solve the securitization equilibrium and the portfolio decision when $d=1.15 \times d^{*}$, or the face value is $15 \%$ greater than in the benchmark case. ${ }^{26}$ This change has two main effects. Firstly, as information asymmetry increases, securitization, or more precisely $q$, decreases much faster than before (the synthetic security is more sensitive to information). Secondly, in the event information asymmetries are low (for $X^{n}$ close to $X_{0}$ ), and securitization volumes are high (since $q$ is still high and $P_{F}$ is higher ${ }^{27}$ due to higher $d$ ), the bank is able to relax the cash constraint significantly. Additionally, as $d$ is greater, the risk protection provided by $F$ is greater and thus the securitization effect on the bank's risk constraint is stronger. As a result, in this scenario securitization leads to larger bank balance sheets and even lower risk premia. For the high information asymmetry case (for $X^{n}$ close to $X_{1}$ ), the effect of lower $q$ is too strong, limiting liquidity creation and thus curtailing balance sheet expansion. Figure 9 shows our results.

Finally, note that in our model all assets are transacted and matured in a single period, hence securitization affects only the portfolio allocation in that period. However, as Adrian and Shin (2010) show, when assets held in the balance sheet (for longer periods) increase in value, that implies a capital gain, which relaxes the risk constraint next period, allowing banks to further increase asset holdings. ${ }^{28}$ Hence, an increase in securitization, which leads to a price increase of all asset due to the higher demand, would lead to asset gains in banks' portfolios, giving further strength to balance sheet increases and

\footnotetext{
${ }^{26}$ That implies in this alternative equilibrium definition only $(i),(i i)$ and $(i v)$ are satisfied (see definition of equilibrium at the beginning of section 3.3).

${ }^{27}$ Note that $P_{F}$ is higher but the expected return of a riskier security, given by $E\left(d-P_{F}\right)$, increases as $d$ increases.

${ }^{28} \mathrm{~A}$ similar argument is also stressed by Danielsson, Shin, and Zigrand (2012). They show that asset revaluations and value-at-risk constraints effectively lead to banks becoming implicitly less risk averse during periods where assets gain in value, generating lower risk premia and lower volatility of asset prices. The mechanism that generates lower risk premia in our model does not rely on the revaluation of bank equity/capital.
} 
Figure 9: Higher Face Value of Synthetic Security
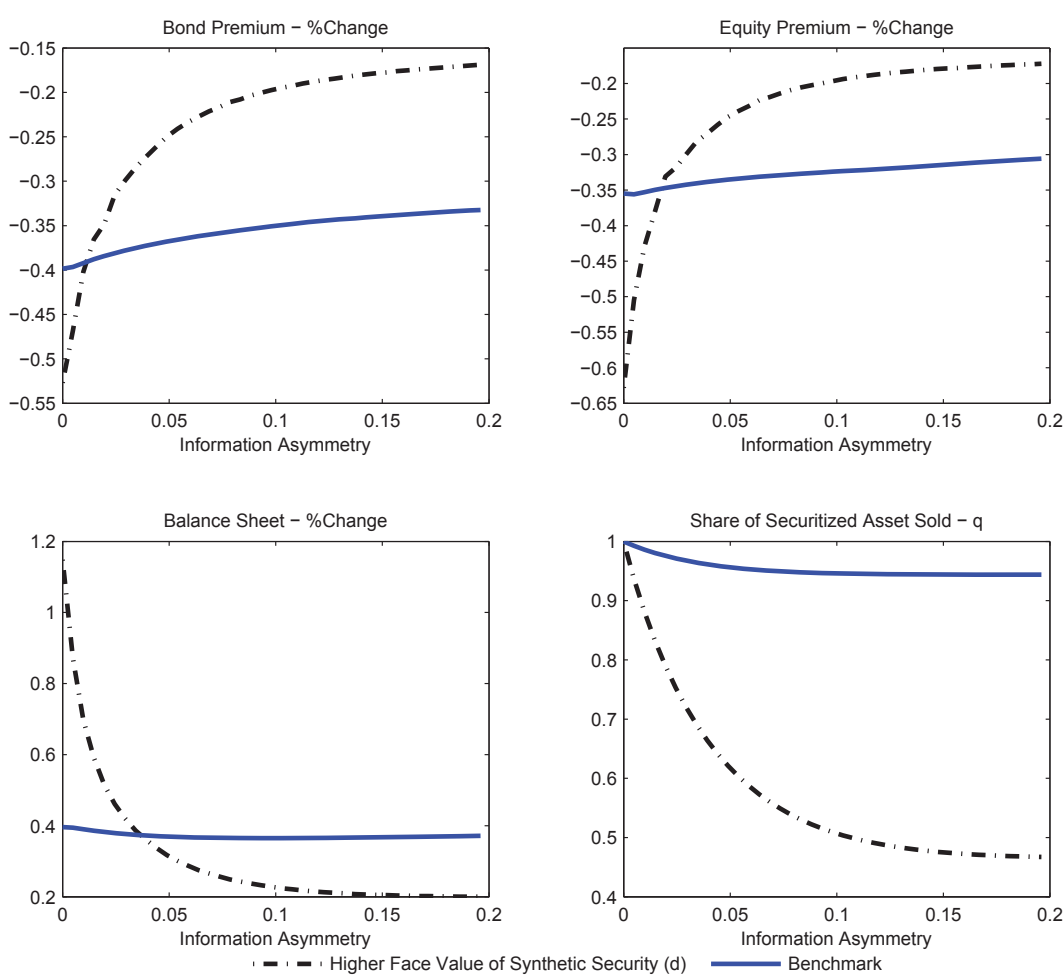

further movements in risk premia in the following periods through the revaluation of bank equity. This feedback mechanism might explain why we observed empirically that the securitization shock continues to affect risk premia for a few periods after the initial shock.

Before we move on to the analysis of the key implications of altering the main parameters of the model we take stock of the main features of our theoretical framework that drive the results. Securitization volume is driven primarily by information asymmetry and thus is orthogonal to asset prices. Due to idiosyncratic credit risk, pooling is optimal, motivating the financial intermediary role in markets. Moreover, due to information asymmetry, tranching is optimal and thus synthetic securities are standard debt contracts. Securitization, due to its asset backing nature, is assumed to be a cheaper form of funding relative to direct borrowing. Securitization, then, leads to a relaxation of cash and risk constraint allowing banks to increase leverage (recall that we empirically verify that securitization and asset holdings of financial entities are positively linked). Banks are marginal price setters facing upward asset supply curves (thus, we implicitly assume some degree of market segmentations exists) and have gains from asset diversification, and thus higher leverage leads to higher demand of assets, generating higher prices and lower premia across different asset classes. Consequently, higher volume of securitization leads to lower risk premia. 


\subsubsection{Sensitivity Analysis}

We perform a number of sensitivity analyses to the parameter values used in the benchmark model. Firstly, we increase the standard deviation of all assets $\left(\sigma, \sigma_{B}, \sigma_{E}\right)$. Secondly, we decrease the price sensitivity of bank demand for credit, bonds, equity and bank borrowing, altering respectively $\left(\mu_{2}, \beta_{B}, \beta_{E}\right.$ and $\left.\kappa\right)$. Thirdly, we alter the correlation structure of asset payoffs. In the first scenario we reverse the sign of all correlation, so assets are all positively correlated, and in the second, we reverse only the credit and equity correlation, leaving government bonds to be negatively correlated to equity and credit. And finally, we decrease the risk aversion of banks (higher $\chi$ ). In all those cases the portfolio channel obtained in the benchmark model remains, more securitization leads to lower risk premia. We discuss each of these scenarios below. Figure 10 shows all the results.

\section{High Variance of Assets}

We start by presenting the results of the model with higher variance of assets. First observe that as variances increase, the SPV is not able to create synthetic securities that are as insensitive to information asymmetry as before, since, given that $Y^{n}$ is more volatile, $f$ is also more volatile for the range $X^{n}>d$. That implies $q$ is lower for any level of information asymmetry. Secondly, as the bank acquires cash and relaxes the cash constraint, it increases asset holdings, which increases risk taking, pushing the allocation closer to a binding risk constraint. Given the higher asset risk, each unit of cash from securitization thus buys more risk than it did in the benchmark case, making the risk constraint more likely to bind for smaller increases in asset holdings. Thus, the balance sheet multiplier of securitization is lower, and consequently, risk premia do not fall as much as before. As we mentioned the variance of a credit basket $(\sigma)$ is related to the risk that is not diversified away in a basket, or the correlation risk of credit assets. We thus conclude that this correlation risk through its impact on securitization volumes, affect the level of risk premia in the economy.

\section{Low Price Sensitivity of Demand for Assets}

We now look at the price sensitivity of demand. By assuming market demand schedules (6), (7) we essentially assume that banks portfolio allocations affect the price of assets or that banks (collectively) are the marginal pricer in the market for assets. We decrease these sensitivities (for all assets, including for bank borrowing) by 30\%. This modification has two main effects. Firstly, when banks cannot use securitization, they set a portfolio of assets that is funded by external borrowing in a way that the cost of funding and the potential gain on assets is such that profits are maximised. As funding costs do not increase as fast as before, bank's utilize more external borrowing and thus hold more assets (bigger balance sheet). As a result, when securitization is allowed the 
bank is not as cash constrainted as before, diminishing the impact of securitization on the size of the balance sheet. Thus, the balance sheet expansion as securitization is allowed is three percentage points smaller under this case than in the benchmark model. Secondly, for any given increase in the demand for equity and bonds, the resulting change in premia is smaller. Hence, under this scenario bond and equity premia do not decrease as much as in the benchmark case. Nonetheless, the introduction of securitization, due to its effect on cash and risk constraints, leads to lower risk premia.

Figure 10: Sensitivity Analysis
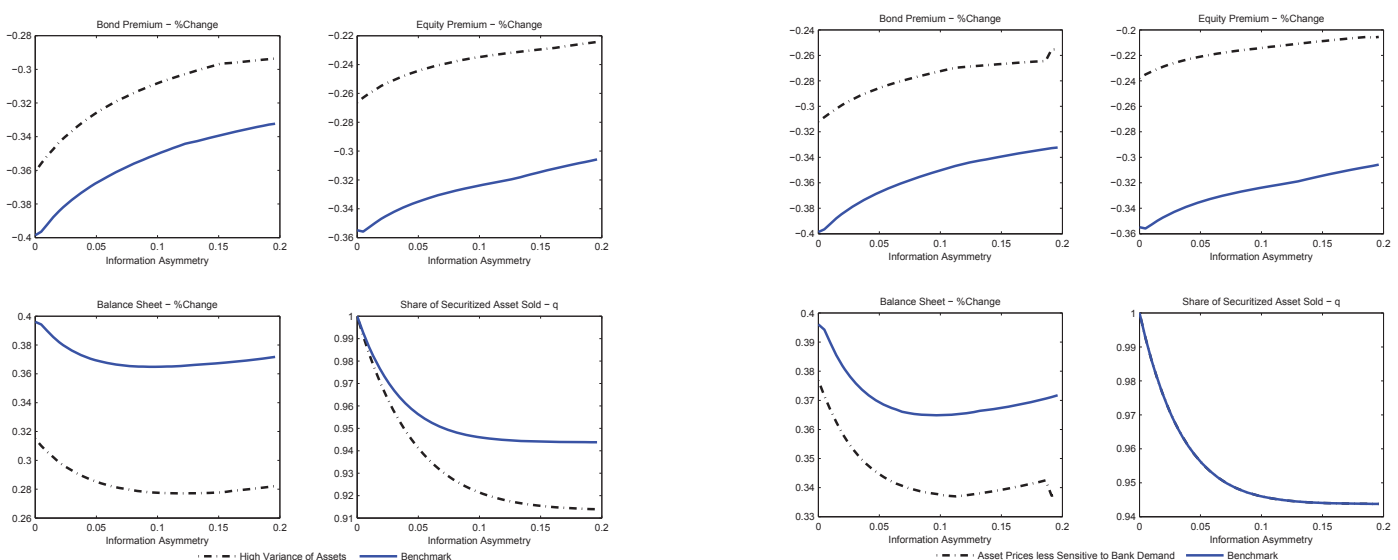

(a) High Variance of Assets

(b) Low Price Sensitivity of Demand
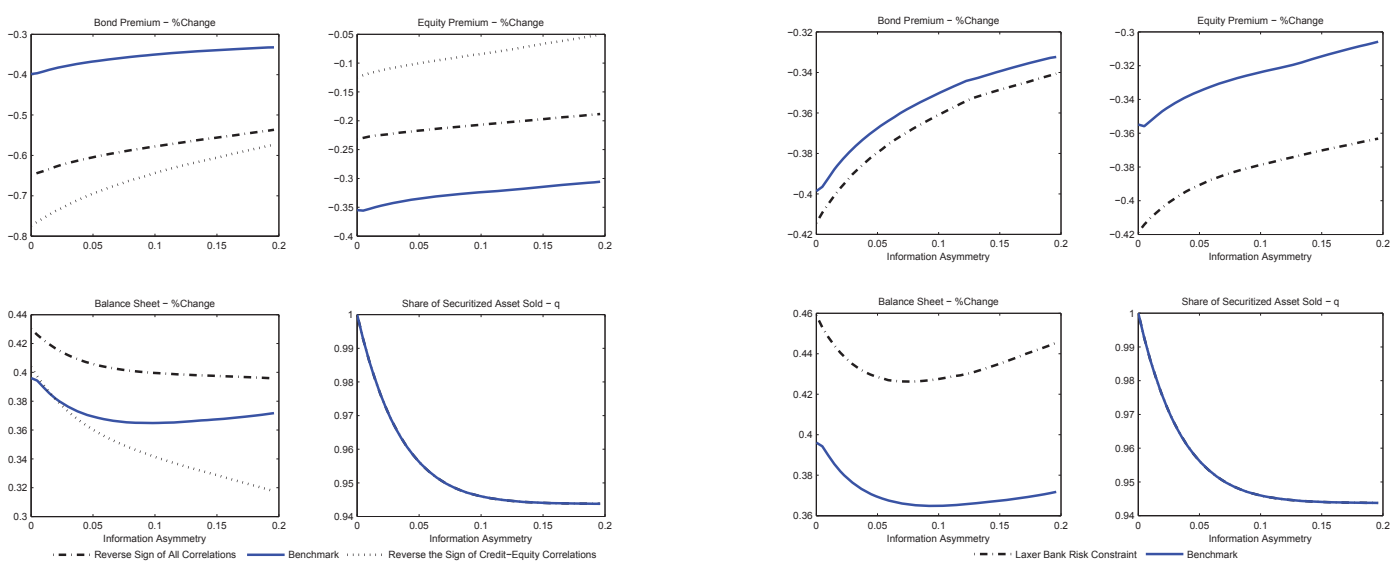

(c) Correlation Structure

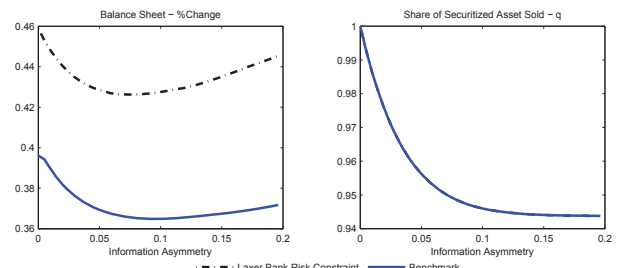

(d) Lower Bank Risk Aversion

\section{New Correlation Structure}

We perform two sensitivity exercises as regards the correlation structure of returns. In the first scenario, we reverse the sign of all correlations such that all assets are positively correlated. In the second scenario we switch the sign of the correlation between credit 
and equity only. When all correlations are positive, the ability of the bank to maximize profits and abide by the risk constraint decreases since assets offer less potential for diversification. As a result, without securitization the bank is very constrained, using little external funding. That implies that when the risk constraint is relaxed due to the ability to securitize credit, the balance sheet can be increased further than in the benchmark case. However, due to the lower diversification role performed by equity and bonds the balance sheet expansion is concentrated on the safest asset, namely bonds. As a result bond premium decreases more than in the benchmark case while equity premium decreases less. When equity and credit are positively correlated, but bonds remain negatively correlated with the other assets, then initial risk constraint is not as strict and thus balance sheet expansions after securitization are smaller than when all correlations were positive. However, bonds are not only the safest asset but also the best provider of diversification. Hence, in scenario 2 bond premium decrease further while equity premium moves very little when compared to scenario 1.

\section{Lower Bank Risk Aversion}

Lastly, we look at the effect of decreasing bank risk aversion, or making the risk constraint laxer by increasing $\chi$ by $30 \%$. As expected we see that given a laxer risk constraint, the introduction of securitization allows banks to increase their balance sheets further than in the benchmark case. However, due to the additional risk capacity available banks favour the riskier asset (but the one that pays higher return), namely equity, over the safer asset, bonds. As a result, bond premium decreases only slightly more compare to the benchmark case, while the equity premium decrease is more substantial under lower risk aversion. Note that in the last three cases the securitization market is not affected, since changes in risk aversion, covariance of risk and price sensitivity of assets demand only affect the portfolio decision, hence $q$ is the same as the one in the benchmark case.

\subsection{Extension}

In the preceding analysis we assumed that the securitization market was independent from the portfolio allocation of banks. Hence, if banks were to increase $Q_{y}$, that would not impact the securitization market, whose equilibrium was obtained for each unit of $F$ or $Q_{y}$. Implicitly, in the separating equilibrium of the market for synthetic securities the final investors would absorb all securities the SPV auctions as long as $P_{F}=E\left[f \mid X^{n}\right]$, or that the security price is equal to its expected value. In this extension we modify the final investor market demand condition by assuming that final investors require that

$$
P_{F}=E\left[F \mid X^{n}\right]-\xi Q_{y}
$$


where $\xi>0$. Thus, under this market assumption, final investors would require an increasing premium to hold a greater volume of synthetic security auctioned by the SPV. We continue to solve the model by looking at the securitization decision first and after that we obtain the portfolio decision. We simplify the securitization decision by taking the security design as given, thus, we assume $F=\min \left(d, Y^{n}\right)$ for an exogenously fixed $d$. The securitization decision therefore only involves the determination of the new separating equilibria

The Bayes-Nash separating equilibrium $\left(q^{*}, P_{F}^{*}\right)$ of the signalling game requires that

- The solution $q^{*}$ is such that $q^{*} \in \arg \max _{q \in[0,1]} q\left(P_{F}(q)-\delta f\right)$ almost surely, and

- The price is $P_{F}^{*}=f-\xi Q_{y}$ almost surely

where $f=E\left[f \mid X=X^{n}\right]$

A separating equilibrium, assuming $(1-\delta) f>\xi Q_{y}$, is given by

$$
q^{*}=\left(\frac{f-\xi Q_{y} /(1-\delta)}{f_{0}-\xi Q_{y} /(1-\delta)}\right)^{-1 /(1-\delta)} \text { and } P_{F}^{*}=f-\xi Q_{y}
$$

with $q^{*}=0$ if $(1-\delta) f<\xi Q_{y}$. See the Appendix for the proof.

The key modification is that now $q^{*}=q\left(f, f_{0}, Q_{y}\right)$ and $P_{F}^{*}=P_{F}\left(f, f_{0}, Q_{y}\right)$ are a function of $Q_{y}$. Thus, the bank must take that into account when solving the portfolio allocation. The portfolio returns are given by

$$
\begin{aligned}
\Pi^{B} \mid X^{n}= & Q_{y}\left(Y^{n}-P_{y}\right)+\mu\left(X^{n}, Q_{y}\right) Q_{y} \\
& +Q_{B}\left(V_{B}-P_{B}\right)+Q_{E}\left(V_{E}-P_{E}\right)-q\left(Q_{y}\right) Q_{y}\left(F-P_{F}\left(Q_{y}\right)\right)-R_{F} \Upsilon
\end{aligned}
$$

The portfolio problem is then given by

$$
\begin{array}{ll}
\max _{\left\{Q_{y}, Q_{B}, Q_{E}, \Upsilon\right\}} & E\left[\Pi^{B} \mid X^{n}\right] \quad \text { s.t. } \\
& Q_{y} P_{y}+Q_{B} P_{B}+Q_{E} P_{E} \leqslant \Gamma_{0}+q\left(Q_{y}\right) Q_{y} P_{F}\left(Q_{y}\right)+\Upsilon \\
& \sigma_{\Pi^{B}} \leqslant \chi \Gamma_{0} .
\end{array}
$$

where

$$
\begin{aligned}
\sigma_{\Pi^{B}} \mid X^{n}= & \left(Q_{y}^{2} \sigma^{2}+Q_{B}^{2} \sigma_{B}^{2}+Q_{E}^{2} \sigma_{E}^{2}+2 Q_{y} Q_{B} \sigma_{y B}+2 Q_{y} Q_{E} \sigma_{y E}+2 Q_{B} Q_{E} \sigma_{E B}\right. \\
& \left.-2 q\left(Q_{y}\right) Q_{y}^{2} \sigma_{F Y}-2 q\left(Q_{y}\right) Q_{y} Q_{B} \sigma_{F B}-2 q\left(Q_{y}\right) Q_{y} Q_{E} \sigma_{F E}+\left(q\left(Q_{y}\right)\right)^{2} Q_{y}^{2} \sigma_{F}^{2}\right)^{1 / 2}
\end{aligned}
$$


Finally, the equilibrium of the model is the defined as the vector of asset allocation $\left\{Q_{y}, Q_{B}, Q_{E}, \Upsilon, q\right\}$ and the vector of prices $\left\{\mu, P_{B}, P_{E}, P_{F}\right\}$ such that $(i)$ given prices and $q\left(Q_{y}\right),\left\{Q_{y}, Q_{B}, Q_{E}, \Upsilon\right\}$ solves problem (11); (ii) given $Q_{y},\left\{q, P_{F}\right\}$ is a separating equilibrium of the signalling game; and (iii) given $\left\{Q_{y}, Q_{B}, Q_{E}\right\}$, prices $\left\{\mu, P_{B}, P_{E}\right\}$ are consistent with the credit spread (mark-up), (5), and the market demand schedules (6) and (7).

Figure 11: Risk Premia in Synthetic Security Market
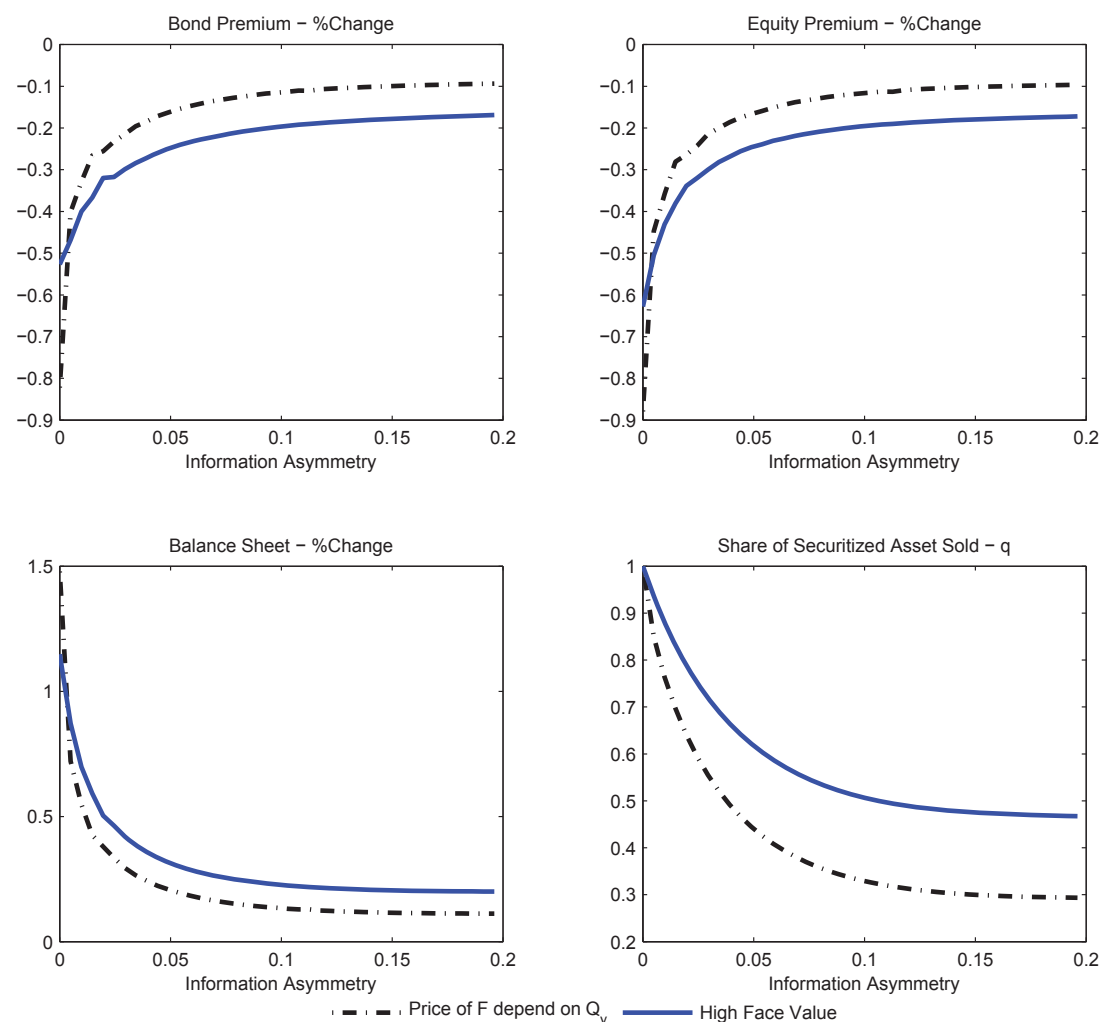

We select the same parameters as in the benchmark model but set $F=\min \left(d, Y^{n}\right)$ with $d=1.15 \times d($ benchmark $)$, or the benchmark model with higher $d$. Furthermore, we set $\xi=0.0015$ ensuring the condition for the separating equilibrium with positive $q^{*}$ holds. Figure 11 shows the results. We find that the share of securitization in equilibrium is always smaller in the alternative model relative to the benchmark model. The intuition for this result is as follows. In the benchmark model SPV has to retain some securities to signal that their value (based on the private information) is above its lower bound. This retention occurs as an optimal response in a Walrasian market where the final investor is trying to ascertain he/she has acquired all information related to the security payoff. Given that in the alternative model the final investors require a premium to buy a security, 
implying a lower bid (for all information states) than in the benchmark case, the optimal retention of the SPV to avoid a further drop in prices is higher (selling synthetic securities became a worst business relative to before). As a result, in a state where signals are good the SPV would hold a bigger share of securities in equilibrium than when the price were equal to its expected value. Naturally, when there is no information asymmetry, given that the preference for cash is higher than the size of the premium, the SPV is willing to sell all securities thus $q=1$ in both the benchmark and the alternative specification. Smaller securitization volumes, as before, imply lower balance sheet expansion and lower drops in asset risk premia. Also note that as a result of the premia paid in the securitization market, bank profits are reduced in the extended model not only due to lower balance sheet expansion but also due to the expected loss in the synthetic security (effectively, the bank is now paying for the risk protection offered by the synthetic security; note that when this price becomes too high the bank may end up doing no securitization). We thus conclude that, if asymmetric information problems exist, the compensation final investors require to bear synthetic securities (tranch related) risk $(\xi)$ influences the volume of securitization, affecting bond and equity premia.

\section{Discussion}

We have shown that the pooling and tranching of assets held on the balance sheet of financial companies not only creates liquidity, alleviating their cash constraint, but also relaxes their risk constraint. Both of these effects allow banks to expand asset holdings, increasing the importance of the sector that is more actively participating in this market relative to the others in the economy (particularly households and firms but also traditional commercial banks), and pushing asset prices up and risk premia down. As a result, although the payoff outlook of assets has remained the same, as do their risk profile, the compensation to undertaking risk in the economy decreases. That way, one implication of our model is that increasing volumes of securitization are associated with low risk premia.

In 2005, the Fed Chairman Alan Greenspan remarked that although the short-term interest rate had been increased by 150 basis points, long-term bond yields had not followed suit, leading to a flat yield curve. This unanticipated behaviour of bond yields was characterized as a conundrum. Rudebusch, Swanson, and Wu (2006) and Backus and Wright (2007), amongst others, have looked at the main causes of (relatively) too low bond yields. The general view is that this was due to a fall in the term premium, probably associated with some combination of diminished macroeconomic and financial market volatility. Our work provide a different channel driving the observed low (and persistent) levels of bond or term premium. The period of 2003 - 2006 experienced a sharp and consistent increase in the volume of ABS transacted in the US. That would have allowed banks to increase their asset allocations, leading to a downward pressure on risk premia. We plot 
the levels of securitization and the bond premium from yearly 2000 until October $2007 .{ }^{29}$ Bond premium and volume of securitization are clearly strongly negatively correlated. ${ }^{30}$ In Aksoy and Basso (2014), we build a macroeconomic model linking term premia with bank liquidity risk, showing how movements in term spread are linked to bank portfolio choice, confirming the conclusion obtained here but employing a standard DSGE model.

Figure 12: ABS issuance versus Bond Premium

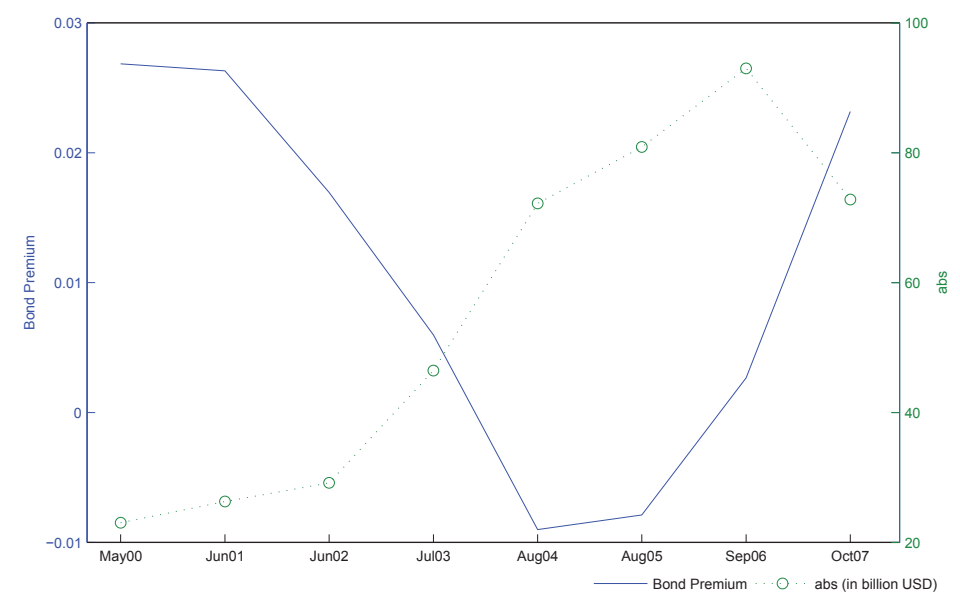

During the same period, the first half of the 2000's, Rajan (2005) also pointed out that current practices in financial intermediation may be a source of shifting risks, but stressed they remained in the system. He focuses particularly on the incentives of bank managers as a driving force in this process. In our model, managers maximize returns using synthetic instruments to increase liquidity creation and to shift some risks to final investors. That allows them to increase asset positions that depressed risk premia in the economy. Nonetheless, the risk profile of the assets remained the same, thus as our model suggests, the compensation for risk is lower (perhaps decreasing the general perception of risk) but the actual volatility of payoffs remained the same.

Another implication of our results is to highlight the importance of looking at financial intermediation, as well as final investors, to increase our understanding of the dynamic movements in asset prices. Many advances in asset pricing (particularly the ones linked to the macroeconomic literature) have focused on different forms of a consumption Euler equation, linking volatility of asset prices with consumption or final investors decision. Recent studies, however, point to the importance of financial intermediation. He and

\footnotetext{
${ }^{29}$ We smoothed the series (6 month cubic spline) to reflect the overall pattern. Note that we perform a robustness test to exclude the period 2003-2006, eliminating the possibility that trends are driving our empirical results. Moreover, our equity premium series does not display any trends.

${ }^{30}$ Note that our empirical results suggest this may not be due to decreased uncertainty or risk perception given that the securitization effect on risk premium remains after controlling for a measure of risk perception (vix).
} 
Krishnamurthy (2013) look at the relevance of capital constraints, particularly during financial crises, in making financial intermediaries be the marginal investors in the market, and hence setting risk premia. Our results show that financial intermediaries' balance sheets can be important in asset pricing even when banking capital is held constant and are not a direct concern. Adrian, Etula, and Muir (2014), like us, also look more generally at the link between financial intermediation and asset pricing. They show that single factor models using shocks to the leverage of security and broker-dealers perform as well as multifactor models in pricing equity and bond portfolios. Instead of looking directly at the growth of assets, our work attempts to look closely at the portfolio choice of financial intermediaries to try to establish the main channels through which their activity influence asset prices. We find that the usage of pooling and tranching of credit assets to be a crucial activity allowing banks to relax both their cash and risk constraints, making them the marginal investor in pricing not only credit but also equity and bonds.

As a result, the link between intermediation and asset prices is directly related to the drivers of the volume of securitization in the economy. The key driver of securitization in the DeMarzo and Duffie's (1999) framework, employed here, is the degree of asymmetric information. ${ }^{31}$ Focusing on informational issues also allow us to stress the optimality of pooling and tranching, key components behind the portfolio mechanism we propose. However, the benchmark model and the extension presented also identify other drivers of the volume of securitization, while holding asymmetric information constant. Firstly, we observe that as the remaining risk of credit baskets (the correlation amongst individual credit instruments or the aggregate risk, denoted by $\eta$ in our model) increases, synthetic securities become more information sensitive and thus final investors are less willing to hold a greater fraction of the tranches created. Secondly, if synthetic securities, due to its potential risks, must offer a premium for its holders (extension in section 3.4), the higher the premium, the lower the volume of securitization. Thus, if agents required lower (higher) compensation to undertake the risk embedded into those tranches ${ }^{32}$, due to for

\footnotetext{
${ }^{31}$ In order to verify the link between the volume of securitization and degree of information asymmetry, validating DeMarzo and Duffie's (1999) framework, we would require data on the degree of asymmetric information or the "forced" retention of synthetic assets on the balance sheet of financial intermediaries during the securitization process. Neither variable is available in our dataset. In a market outcome, if retention is not done, $P_{F}$, the price of the security at the auction day, must decrease. Deal prices are available in our sample, and thus we construct a monthly price discount variable given by $\sum_{\text {tranches }}(100-$ $\left.P_{F}\right) \times($ Face Value of tranch $) /$ Volume Securitization for each month. Another implication of the model is that the lower $d$ (the safer the tranches), the higher $q$ will be, implying potentially higher volumes of securitization. We thus calculate the ratio of AAA rated tranches to the total volume of securitization per month. We then regress these two variables on the volume of securitization (we are only after correlation, not being able to establish causality). We find that both variables are significant and as expected the higher the price discount, the lower the total amount of securitization (measured as face value) and the higher the ratio of triple AAA rated tranches, the higher the volume of securitization. Results are available from the authors upon request.

${ }^{32}$ This movement in compensation must be orthogonal to the risk compensation require to hold equities and bonds.
} 
instance, misunderstanding of the risks involved in triple AAA synthetic securities (Coval, Jurek, and Stafford (2009)), due to institutional investors' sentiment (Ivashina and Sun (2011)) or due to miscalculation of the probability of rare events (Gennaioli, Shleifer, and Vishny (2010)), then levels of securitization will be higher (lower). ${ }^{33}$ Therefore, securitization volumes may vary due to the fluctuations in the degree of information asymmetry, in the (mis) perceived credit basket riskiness or in the compensation to undertake tranche related risk (which are unrelated to equity and bond markets). As long as pooling and tranching is done, allowing banks to relax cash and risk constraints, the portfolio mechanism highlighted here will link variations in securitization to bond and equity premia. ${ }^{34}$

Our model took the degree of information asymmetry as given and provided a solution whereby in equilibrium all agents become aware of all information while pricing the credit basket. However, we note that the incentives for bank managers is to increase actual information asymmetry, since that way they obtain better conditions in the origination of credit assets (loans) but would like to decrease the "perceived" information asymmetry when compared to final investors in the distribution market. That way they would maximize the liquidity creation of the securities on their balance sheet. This might have generated strong conflict of interests between the different divisions in large financial corporations. That would be particularly the case since these institutions not only participate in the origination and distribution of assets, but also act as final investors (through different funds) and investment advisors for final investors. ${ }^{35}$ Thus, modelling the acquisition of information and the agency problems involved are then crucial to understand the risk implications of securitization and bank portfolio choices. Building on the framework discussed here, one interesting (but potentially cumbersome) extension would be to relax the assumption that $X_{0}$ (the lower bound of the information set) is common knowledge, incorporating a signal extraction mechanism that opens the possibility of misinformation. For instance, Piskorski, Seru, and Witkin (2013) document that buyers received false information about the true quality of assets in contractual disclosures by intermediaries during the sale of mortgages.

Finally, our theoretical model, by looking at the portfolio choice of financial entities, provides a rationale for the empirically observed link between securitization and asset prices. An alternative explanation is that deeper securitization markets, by introducing new assets in the economy, provide additional insurance instruments previously unavai-

\footnotetext{
${ }^{33}$ There is evidence these factors played an important role in the surge of securitization during the 2003 - 2007 period (Chernenko, Hanson, and Sunderam (2013)).

${ }^{34}$ Note also that although our model is static, the main mechanism highlighted here can also carry through in a dynamic model where the main drivers of securitization, namely, the degree of information asymmetry, credit basket riskiness and compensation to undertake tranche related risk, vary through time.

${ }^{35}$ This conflict of interest might have been manifested in the last crisis. For instance, reports suggest that "JPMorgan Chase \& Co said it routinely overstated the quality of mortgages it was selling to investors, and it agreed to pay 13 billion USD to settle related charges with the U.S. government, federal officials said on Tuesday." (Reuters (Nov. 19, 2013))
} 
lable, depressing risk premia. However, while volumes of securitization have trended positively from 1993 until the crisis, we do not observe such trends in bond and equity premia. Moreover, Simsek (2013) shows that under heterogenous believes, financial innovation or the introduction of new assets, due to enhanced speculation motives, may push risk premium up, offsetting the insurance effect. Nonetheless, other mechanisms explaining the link between securitization and asset prices might also be at play.

\section{Final Remarks}

The volume of transactions in the securitization market has increased substantially since the beginning of the 90's. Using a monthly dataset of asset-backed securities (ABS) and mortgage backed securities (MBS) transactions in the US we find that increases in the volume of ABS transacted affect both the bond and the equity premium. This effect is not related to aggregate risk nor the link between volume traded and economic or asset payoff outlook. Thus, the empirical results point to the relationship between financial intermediation and asset prices. Consequently, we build a model that focuses particularly on the portfolio choice of banks when securitization of credit assets held on the balance sheet is feasible. We show that an increase in securitization leads to lower equity and bond premium since creating and selling synthetic securities relaxes both the cash and the risk constraint of banks. Thus, the key variables to understand the link between financial intermediation and asset prices are the main drivers of securitization volumes, namely degree of asymmetric information, the pricing of the correlation risk of credit baskets and the assessment of the final investors compensation for undertaking tranche related risk.

A number of different extensions to our framework, both empirically and theoretically, may prove to be fruitful research projects. First, looking at micro bank data, particularly at portfolio compositions during periods of high volume of ABS and MBS issuance might clarify the main channel, which was explored here only at the aggregate level. Second, our model characterized a partial equilibrium of bank portfolio choice. Extending the framework to a general equilibrium model, which also incorporates some form of market segmentation, is important to understand the effects of this process to other asset holders. Our results point to importance of information asymmetry between intermediaries and final investors. Studying the information acquisition process of credit basket's payoff and risk (correlation of individual credit assets) may improve our understanding of the effects of financial intermediation on asset prices. Finally, Chabakauri (2014) provides an analytical survey on the differential effects of borrowing and short sale constraints and limited participation on asset prices in an environment where final investors have heterogenous preferences and beliefs. Extending our framework to incorporate final investor constraints may be relevant to explore the impact of securitization on asset prices. 


\section{References}

Acharya, V. V., P. Schnabl, And G. Suarez (2013): "Securitization without risk transfer," Journal of Financial Economics, 107(3), 515-536.

Adrian, T., E. Etula, and T. Muir (2014): "Financial Intermediaries and the CrossSection of Asset Returns," The Journal of Finance, 69(6), 2557-2596.

Adrian, T., E. Moench, and H. S. Shin (2010): "Financial Intermediation, Asset Prices, and Macroeconomic Dynamics," Staff Reports 422, Working Paper, Federal Reserve Bank of New York.

Adrian, T., And H. S. Shin (2008): "Procyclical leverage and value-at-risk," Staff Reports 338, Federal Reserve Bank of New York.

(2010): "Financial Intermediaries and Monetary Economics," in Handbook of Monetary Economics, ed. by B. M. Friedman, and M. Woodford, vol. 3, chap. 12, pp. 601-650. Elsevier.

Aksoy, Y., And H. S. Basso (2014): "Liquidity, Term Spreads and Monetary Policy," The Economic Journal, 124(581), 1234-1278.

Altunbas, Y., L. Gambacorta, and D. Marques-Ibanez (2009): "Securitisation and the bank lending channel," European Economic Review, 53(8), 996-1009.

Andrews, D. W. K. (1993): "Tests for Parameter Instability and Structural Change with Unknown Change Point," Econometrica, 61(4), 821-56.

Andrews, D. W. K., and W. Ploberger (1994): "Optimal Tests When a Nuisance Parameter Is Present Only under the Alternative," Econometrica, 62(6), 1383-1414.

Backus, D. K., And J. H. Wright (2007): "Cracking the Conundrum," Brookings Papers on Economic Activity, 38(1), 293-329.

Barsky, R. B., And E. R. Sims (2011): "News shocks and business cycles," Journal of Monetary Economics, 58(3), 273-289.

Bertaut, C. C., and R. W. Tryon (2007): "Monthly estimates of U.S. cross-border securities positions," International Finance Discussion Papers 910, Board of Governors of the Federal Reserve System (U.S.).

Campbell, J. Y., Y. L. Chan, and L. M. Viceira (2003): "A multivariate model of strategic asset allocation," Journal of Financial Economics, 67(1), 41-80. 
Campbell, J. Y., and L. M. Viceira (1999): "Consumption And Portfolio Decisions When Expected Returns Are Time Varying," The Quarterly Journal of Economics, 114(2), 433-495.

Chabakauri, G. (2014): "Asset Pricing with Heterogeneous Preferences, Beliefs and Portfolio Constraints," Journal of Monetary Economics, forthcoming.

Chernenko, S., S. G. Hanson, and A. Sunderam (2013): "The Rise and Fall of Securitization," Working paper, Harvard University.

Christiano, L. J., M. Eichenbaum, and C. L. Evans (1999): "Monetary policy shocks: What have we learned and to what end?," in Handbook of Macroeconomics, ed. by J. B. Taylor, and M. Woodford, vol. 1 of Handbook of Macroeconomics, chap. 2, pp. 65-148. Elsevier.

Cochrane, J. H., and M. Piazzesi (2005): "Bond Risk Premia," American Economic Review, 95(1), 138-160.

Coval, J. D., J. W. Jurek, and E. Stafford (2009): "Economic Catastrophe Bonds," American Economic Review, 99(3), 628-66.

Danielsson, J., H. S. Shin, and J.-P. Zigrand (2012): "Balance Sheet Capacity and Endogenous Risk," Working paper, LSE - mimeo.

DeMarzo, P., and D. Duffie (1999): "A Liquidity-Based Model of Security Design," Econometrica, 67(1), 65-100.

DeMarzo, P. M. (2005): "The Pooling and Tranching of Securities: A Model of Informed Intermediation," Review of Financial Studies, 18(1), 1-35.

Fostel, A., And J. Geanakoplos (2012): "Tranching, CDS, and Asset Prices: How Financial Innovation Can Cause Bubbles and Crashes," American Economic Journal: Macroeconomics, 4(1), 190-225.

Gennaioli, N., A. Shleifer, and R. W. Vishny (2010): "Neglected Risks, Financial Innovation, and Financial Fragility," NBER Working Papers 16068, National Bureau of Economic Research, Inc.

Gilchrist, S., and E. Zakrajsek (2012): "Credit Spreads and Business Cycle Fluctuations," American Economic Review, 102(4), 1692-1720.

Gurkaynak, R. S., B. Sack, and J. H. Wright (2007): "The U.S. Treasury yield curve: 1961 to the present," Journal of Monetary Economics, 54(8), 2291-2304. 
Hansen, B. E. (2000): "Testing for structural change in conditional models," Journal of Econometrics, 97(1), 93-115.

He, Z., and A. Krishnamurthy (2013): "Intermediary Asset Pricing," American Economic Review, 103(2), 732-70.

Ivashina, V., AND Z. Sun (2011): "Institutional demand pressure and the cost of corporate loans," Journal of Financial Economics, 99(3), 500-522.

Jiménez, G., A. R. Mian, J.-L. Peydró, and J. Saurina (2010): "Local Versus Aggregate Lending Channels: The Effects Of Securitization On Corporate Credit Supply In Spain," NBER Working Papers 16595, National Bureau of Economic Research, Inc.

Kilian, L. (1998): "Small-Sample Confidence Intervals For Impulse Response Functions," The Review of Economics and Statistics, 80(2), 218-230.

Loutskina, E., And P. E. Strahan (2009): "Securitization and the Declining Impact of Bank Finance on Loan Supply: Evidence from Mortgage Originations," The Journal of Finance, 64(2), 861-889.

Piskorski, T., A. Seru, And J. Witkin (2013): "Asset Quality Misrepresentation by Financial Intermediaries: Evidence from RMBS Market," NBER Working Papers 18843, National Bureau of Economic Research, Inc.

RAJAn, R. G. (2005): "Has financial development made the world riskier?," Proceedings, (Aug), 313-369.

Reuters (Nov. 19, 2013): "JPMorgan says "mea culpa" in $\$ 13$ billion settlement with U.S," Reuters.

Rudebusch, G. D., E. T. Swanson, and T. Wu (2006): "The Bond Yield "Conundrum"; from a Macro-Finance Perspective," Monetary and Economic Studies, 24(S1), 83-109.

Simsek, A. (2013): "Speculation and Risk Sharing with New Financial Assets," The Quarterly Journal of Economics, 128(3), 1365-1396. 


\section{Appendix A. Robustness of Empirical Results}

\subsection{Benchmark}

\section{Benchmark - Sample Period 01/1993 until 12/2002}

This sample excludes the boom period of securitization occurred from 2003 until the financial crisis. The VAR specification remains unchanged. Impulse responses for bond

Figure 13: Impulse Responses - Parsimonious Model - Sample Period 01/1993 until $12 / 2002$
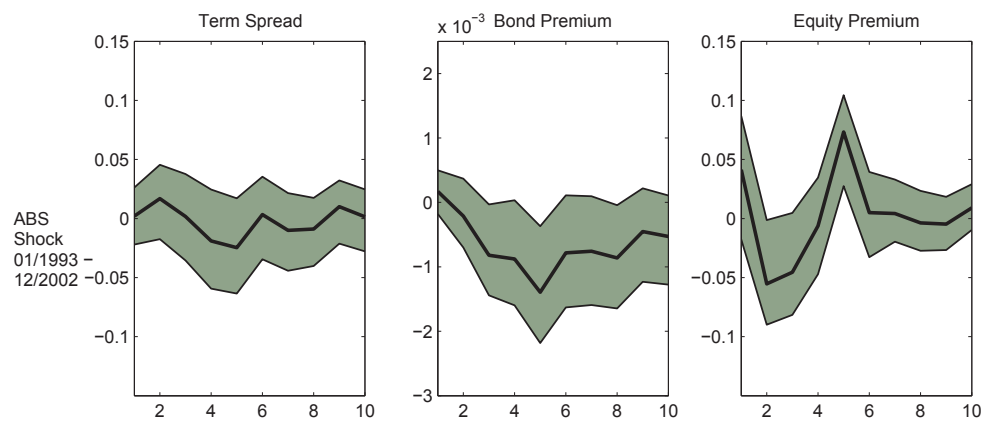

premium and equity premium obtained are very similar to the benchmark case, however, the contribution of a securitization shock in explaining FEV of bond and equity premia decreases from around $6-7 \%$, observed in the benchmark case, to around $3-4 \%$.

Benchmark - Sample Period 01/2009 until 09/2013

This estimation allows us to analysis the link between securitization and asset prices in the post-crisis period. The VAR specification remains unchanged. Impulse responses

Figure 14: Impulse Responses - Parsimonious Model - Sample Period 01/2009 until $09 / 2013$
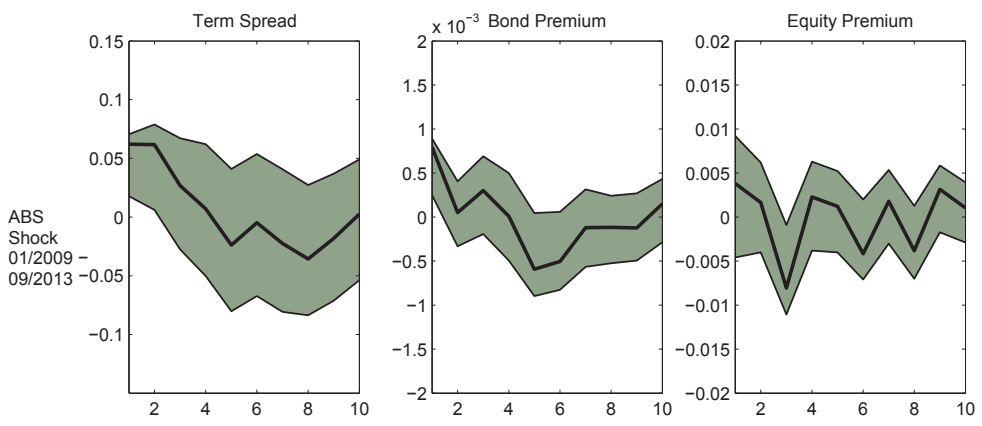

for bond premium and equity premium obtained are somewhat similar to the benchmark case. We find that a securitization shock contributes in explaining around $6 \%$ of $\mathrm{FEV}$ in excess bond return and around 5\% of FEV in excess market return, similar to what we obtained in the benchmark case. 
Robustness Check on Identification We perform two robustness check on our recursive identification assumption. Firstly we reverse the order of the securitization variable putting it last in the vector of variables, thus all asset prices can only respond to securitization with a lag. Secondly, we obtain the contemporaneous response of securitization to shocks in spreads, excess bond and market returns, verifying whether reverse causality was a possibility. Change the ordering only affects the negative movement observed for spreads in the benchmark estimation. Reverse causality does not seem to occur, or securitization does not respond to shocks to risk premia or the only statistically significant response is positive.

Figure 15: Impulse Responses - Reverse Ordering
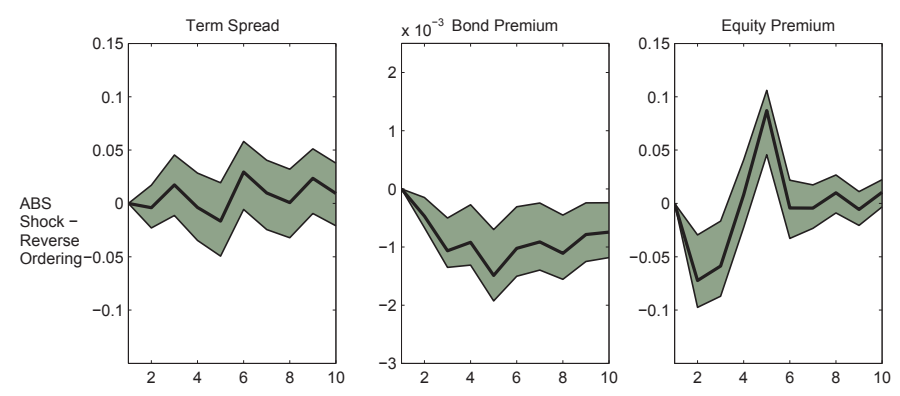

Figure 16: Impulse Responses - ABS response to asset price shocks
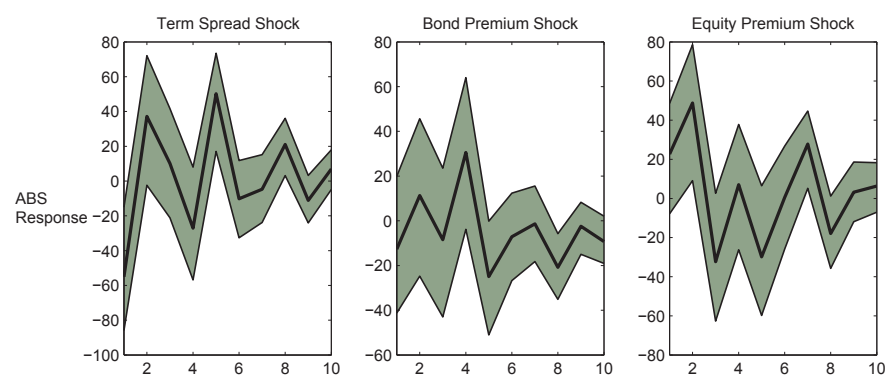

\subsection{Additional Robustness}

In figure 17 we show that controlling for foreign demand for U.S. assets does not impact the mechanism by which securitization affects asset prices.

\subsection{Quarterly Data}

We now turn to the results of the estimations using quarterly data. The main reason to use this frequency is that we can then control for the asset holdings of securities and brokers dealers, which other studies have shown to be important in explaining asset prices. 
The first figure below shows the estimations when either securitization or asset holdings is included in the VAR. The second figure shows the impulse responses to a securitization shock when both variables are included in the VAR. We observe that controlling for asset

Figure 17: Augmented Models - Foreign demand for U.S. assets
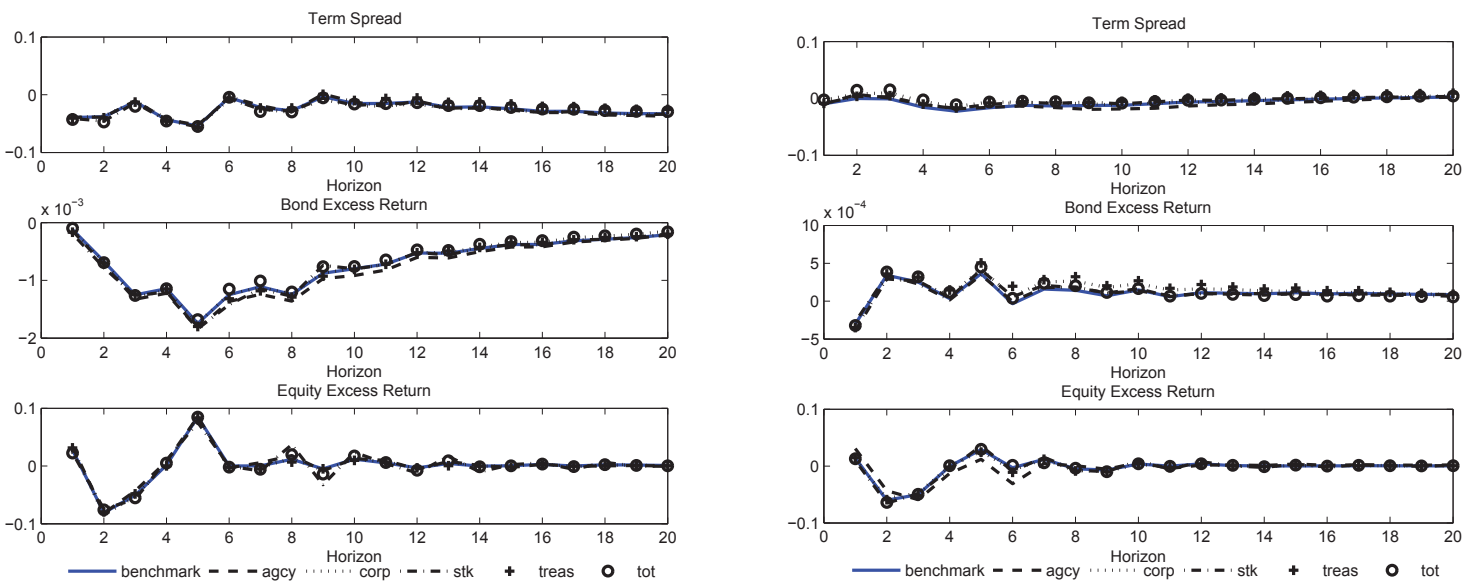

(a) Impulse Response to Asset-backed Securities

(b) Impulse Response to Mortgage-backed Securities

growth of these financial institutions does not altered the explanatory power of securitization and that a shock to securitization leads to a sharp increase in asset holdings, supporting the portfolio link explored in the theoretical model.

Figure 18: Impulse Responses - Quarterly Frequency - Benchmark
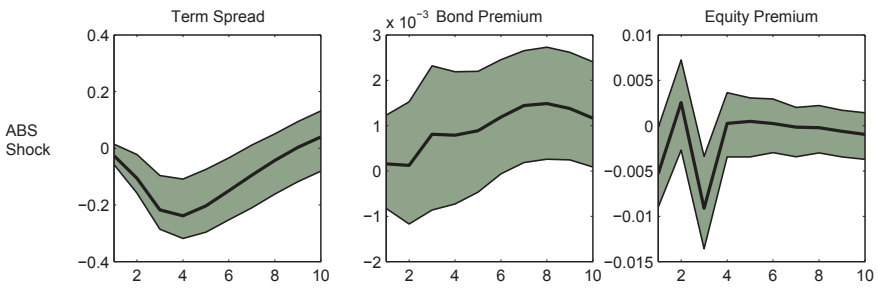

\subsection{Predictive Regressions}




\section{Appendix B. Risk Profile of the Synthetic Asset $F$}

In this appendix we show the details of the derivation of the variance of asset $F$ and its covariance with the other three assets, namely, the credit basket, government bonds and equity.

The variance of $F$ is given by

Predictive Regressions- OLS Estimates 1993M1-2007M11

\begin{tabular}{|c|c|c|c|}
\hline & spread & $x b r$ & $x r$ \\
\hline$d A B S_{t-1}$ & -0.0115 & -0.0015 & -0.2247 \\
\hline$d A B S_{t-2}$ & 0.0627 & $-0.0024^{*}$ & $-0.3718^{* *}$ \\
\hline$d A B S_{t-3}$ & -0.0458 & -0.0002 & -0.2807 \\
\hline$d A B S_{t-4}$ & $-0.1776^{* *}$ & -0.0018 & 0.1259 \\
\hline$r p d_{t-1}$ & -1.5549 & 0.0185 & 1.3005 \\
\hline$r p d_{t-2}$ & -1.2749 & -0.0233 & -3.2139 \\
\hline$r p d_{t-3}$ & 1.8857 & 0.0011 & 1.6579 \\
\hline$r p d_{t-4}$ & 0.9081 & 0.0036 & 0.2732 \\
\hline spread $_{t-1}$ & $0.9497^{* * *}$ & $0.0067^{* * *}$ & 0.2499 \\
\hline spread $_{t-2}$ & $-0.2746^{* *}$ & $-0.0074^{* * *}$ & -0.2934 \\
\hline $\operatorname{spread}_{t-3}$ & $0.3544^{* * *}$ & 0.0011 & -0.114 \\
\hline spread $_{t-4}$ & -0.0696 & -0.0008 & 0.2041 \\
\hline$x b r_{t-1}$ & 3.7802 & $0.9335^{* * *}$ & $-23.1635^{* *}$ \\
\hline$x b r_{t-2}$ & -4.4753 & 0.1566 & 22.3724 \\
\hline$x b r_{t-3}$ & -1.3059 & -0.0332 & 3.7552 \\
\hline$x b r_{t-4}$ & -1.938 & -0.0926 & -13.1742 \\
\hline$x r_{t-1}$ & -0.0582 & $0.0022^{* *}$ & 0.0612 \\
\hline$x r_{t-2}$ & $-0.1647^{*}$ & 0.0003 & -0.0823 \\
\hline$x r_{t-3}$ & $-0.1608^{*}$ & -0.0009 & -0.1122 \\
\hline$x r_{t-4}$ & 0.0702 & 0.0006 & -0.0639 \\
\hline realr_3$m_{t-1}$ & 0.01 & $0.0053^{* * *}$ & 0.0388 \\
\hline realr_3$m_{t-2}$ & $-0.3682^{* *}$ & $-0.0057^{* * *}$ & 0.0043 \\
\hline realr_3 $3 m_{t-3}$ & 0.1685 & -0.001 & -0.3308 \\
\hline realr_3 $3 m_{t-4}$ & 0.1744 & 0.0015 & $0.3195^{*}$ \\
\hline$R^{2}$ & 0.9161 & 0.9372 & 0.166 \\
\hline n.o.b. & 175 & 175 & 175 \\
\hline
\end{tabular}


Figure 19: Impulse Responses - Quarterly Frequency
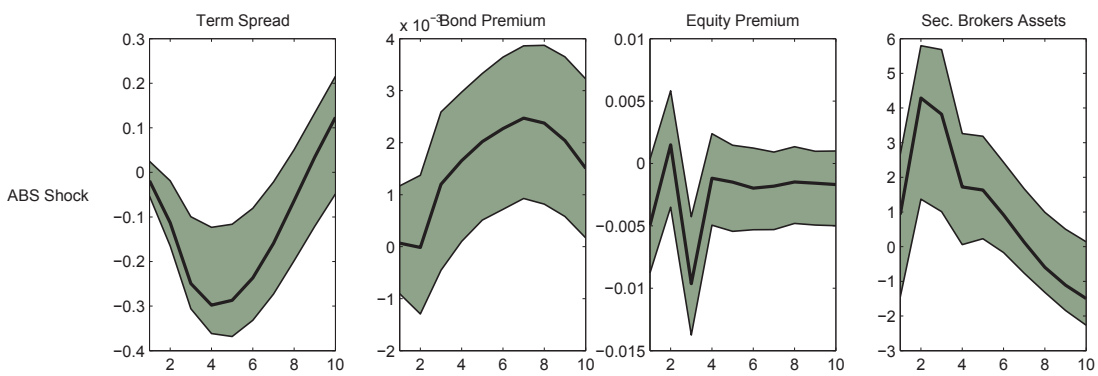

(a) Securitization and Asset Holdings of Sec. Brokers
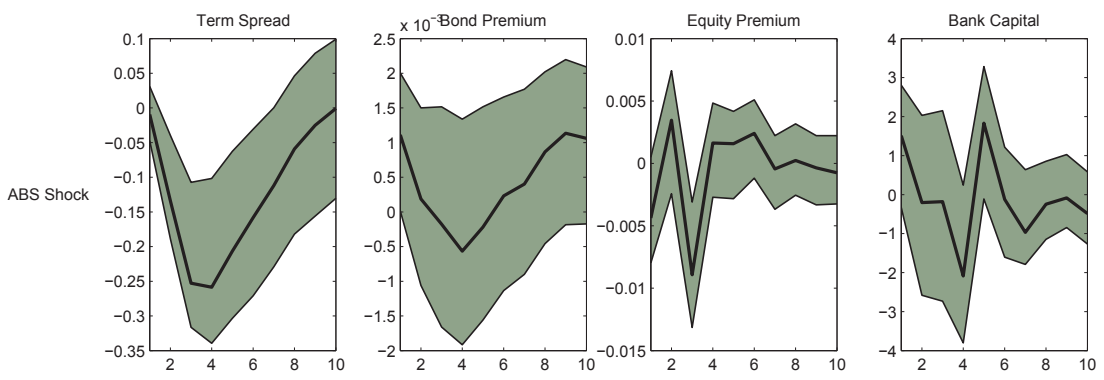

(b) Securitization and Bank Capital

$$
\begin{aligned}
\sigma_{F}^{2} & =\int_{-\infty}^{\infty}\left(F-E\left[F \mid X^{n}\right]\right)^{2} f(\eta) d \eta=\int_{-\infty}^{\infty}\left(\min \left(d, X^{n}+\eta\right)-E\left[F \mid X^{n}\right]\right)^{2} f(\eta) d \eta \\
\sigma_{F}^{2} & =\int_{-\infty}^{\left(d-X^{n}\right)}\left(X^{n}+\eta\right)^{2} f(\eta) d \eta+\int_{\left(d-X^{n}\right)}^{\infty} d^{2} f(\eta) d \eta-\left(f^{d}\right)^{2} \\
\sigma_{F}^{2} & =\left(X^{n}\right)^{2} \Phi\left(\frac{d-X^{n}}{\sigma}\right)-2 X^{n} \sigma \phi\left(\frac{d-X^{n}}{\sigma}\right)-\sigma^{2}\left[\frac{d-X^{n}}{\sigma} \phi\left(\frac{d-X^{n}}{\sigma}\right)-\Phi\left(\frac{d-X^{n}}{\sigma}\right)\right]+d^{2}\left[1-\Phi\left(\frac{d-X^{n}}{\sigma}\right)\right]-\left(f^{d}\right)^{2}
\end{aligned}
$$

The covariance between the synthetic asset $F$ and the credit basket $Y^{n}$ is given by

$$
\begin{aligned}
\sigma_{F y}= & \int_{-\infty}^{\infty}\left(F-E\left[F \mid X^{n}\right]\right)\left(X^{n}+\eta-X^{n}\right) f(\eta) d \eta=\int_{-\infty}^{\infty} \min \left(d, X^{n}+\eta\right)\left(X^{n}+\eta\right) f(\eta) d \eta \\
\sigma_{F y}= & \int_{-\infty}^{\left(d-X^{n}\right)}\left(X^{n}+\eta\right)^{2} f(\eta) d \eta+\int_{\left(d-X^{n}\right)}^{\infty} d\left(X^{n}+\eta\right) f(\eta) d \eta-f^{d} X^{n} \\
\sigma_{F y}= & \left(X^{n}\right)^{2} \Phi\left(\frac{d-X^{n}}{\sigma}\right)-2 X^{n} \sigma \phi\left(\frac{d-X^{n}}{\sigma}\right)-\sigma^{2}\left[\frac{d-X^{n}}{\sigma} \phi\left(\frac{d-X^{n}}{\sigma}\right)-\Phi\left(\frac{d-X^{n}}{\sigma}\right)\right] \\
& +d\left[X^{n}\left(1-\Phi\left(\frac{d-X^{n}}{\sigma}\right)\right)+\sigma \phi\left(\frac{d-X^{n}}{\sigma}\right)\right]-f^{d} X^{n}
\end{aligned}
$$


The covariance between the synthetic asset $F$ and equity (where $f\left(\eta, V_{E}\right)$ is the joint density function of the aggregate credit risk and the equity risk) is given by

$$
\begin{aligned}
\sigma_{F E} & =\int_{-\infty}^{\infty} \int_{-\infty}^{\infty} \min \left(d, X^{n}+\eta\right) V_{E} f\left(\eta, V_{E}\right) d \eta d V_{E} \\
\sigma_{F E} & =\int_{-\infty}^{\infty} \int_{-\infty}^{\left(d-X^{n}\right)}\left(X^{n}+\eta\right) V_{E} f(\eta) d \eta+\int_{\left(d-X^{n}\right)}^{\infty} V_{E}\left(X^{n}+\eta\right) f(\eta) d \eta-f^{d} X^{n}
\end{aligned}
$$

Due to the multivariate density function we can not obtain analytical solutions.

However, note that $F=Y^{n}$ if $\eta<d-X^{n}$ and is constant otherwise, thus we use $\sigma_{F E} \approx \operatorname{Prob}\left(\eta<d-X^{n}\right) \sigma_{E y}=\Phi\left(\frac{d-X^{n}}{\sigma}\right) \sigma_{E y}$

Using the same argument $\sigma_{F B} \approx \operatorname{Prob}\left(\eta<d-X^{n}\right) \sigma_{B y}=\Phi\left(\frac{d-X^{n}}{\sigma}\right) \sigma_{B y}$. 


\section{Appendix C. Accuracy of Optimization and Linear Inter- polation}

All results reported in the section 3 are smoothed due to potential accuracy problems in the numerical solution of the portfolio optimization problem. We find as we change $X^{n}$ from $X_{0}$ to $X_{1}$ the portfolio solution for the case when no securitization is allowed does not change. However, in some cases a small change in $X^{n}$ result in a more sizable movement in the portfolio allocations. This may be due to the fact that the lagrangian of the optimization problem is very insensitive to small changes to the portfolio holdings as $X^{n}$ changes. As a result, the optimization routine finds it optimal to maintain asset holdings fixed, increasing external funding $(\Upsilon)$ only to satisfy the cash constraint (recall that $P_{y}$ increases as $X^{n}$ increases) leaving the other constraint (risk) unaffected. As $X^{n}$ continues to increase, a re-balancing is finally optimal under the accuracy used by the optimization routine and the portfolio allocations change. This produces a stepwise solution to portfolio holdings for the model without securitization. This does not occur with the model with securitization since $X^{n}$ affects $q$ leading to changes in both constraints and the objective function when $X^{n}$ changes. In order to smooth the portfolio choice, possibly correcting for accuracy problems, we interpolate linearly the solutions across $X^{n}$. Figure 13 displays the raw solution and the linearly interpolated solutions for the Benchmark model. Note that this does not affect the main conclusions of our model. 


\section{Appendix D. Separating Equilibrium - Extension}

Under the alternative specification for the market demand the monotonicity of $q^{*}$, as well as the single crossing property, shown in DeMarzo and Duffie (1999), continue to hold. Thus, to ensure $q^{*}$ is optimal we need only check the first-order condition of the informed

Figure 20: Accuracy and Linear Interpolation
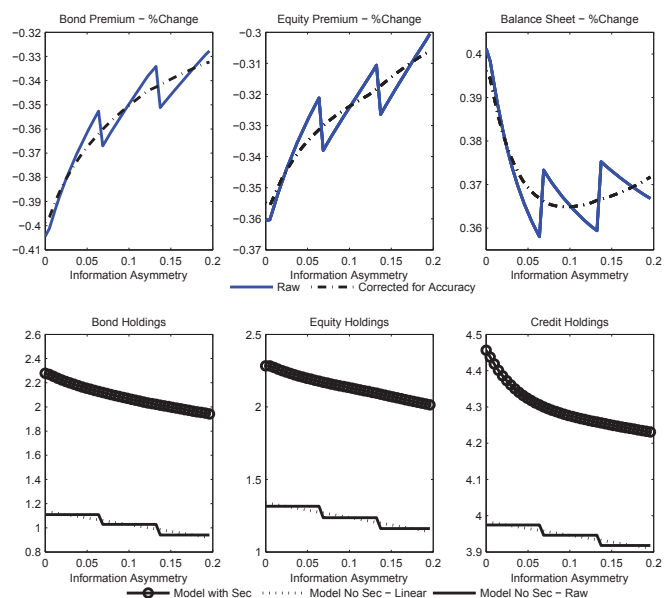

agent's optimization problem (see DeMarzo and Duffie (1999) for details). The first order condition of the SPV (assuming interior solution) is

$$
q \frac{d P_{F}^{*}}{d q}+\left(P_{F}^{*}-\delta f\right)=0
$$

Substituting for the Bayes-Nash equilibrium condition ( $i i)$ gives

$$
\frac{d P_{F}^{*}}{d q}+\frac{(1-\delta)}{q} P_{F}^{*}=\frac{\delta f \xi Q_{y}}{q}
$$

The separating equilibrium is given by a the solution to this differential equation with the boundary condition that $P_{F}^{*}(1)=f_{0}-\xi Q_{y}$. Note that if $(1-\delta) f<\xi Q_{y}$ then it is optimal to SPV to set $q^{*}=0$ for all $X^{n}$ (in this case the solution to SPV problem is not interior). 


\title{
BANCO DE ESPAÑA PUBLICATIONS
}

\author{
WORKING PAPERS
}

1401 TERESA SASTRE and FRANCESCA VIANI: Countries' safety and competitiveness, and the estimation of current account misalignments.

1402 FERNANDO BRONER, ALBERTO MARTIN, AITOR ERCE and JAUME VENTURA: Sovereign debt markets in turbulent times: creditor discrimination and crowding-out effects.

1403 JAVIER J. PÉREZ and ROCÍO PRIETO: The structure of sub-national public debt: liquidity vs credit risks.

1404 BING XU, ADRIAN VAN RIXTEL and MICHIEL VAN LEUVENSTEIJN: Measuring bank competition in China: a comparison of new versus conventional approaches applied to loan markets.

1405 MIGUEL GARCÍA-POSADA and JUAN S. MORA-SANGUINETTI: Entrepreneurship and enforcement institutions: disaggregated evidence for Spain.

1406 MARIYA HAKE, FERNANDO LÓPEZ-VICENTE and LUIS MOLINA: Do the drivers of loan dollarisation differ between CESEE and Latin America? A meta-analysis.

1407 JOSÉ MANUEL MONTERO and ALBERTO URTASUN: Price-cost mark-ups in the Spanish economy: a microeconomic perspective.

1408 FRANCISCO DE CASTRO, FRANCISCO MARTÍ, ANTONIO MONTESINOS, JAVIER J. PÉREZ and A. JESÚS SÁNCHEZ-FUENTES: Fiscal policies in Spain: main stylised facts revisited.

1409 MARÍA J. NIETO: Third-country relations in the Directive establishing a framework for the recovery and resolution of credit institutions.

1410 ÓSCAR ARCE and SERGIO MAYORDOMO: Short-sale constraints and financial stability: evidence from the Spanish market.

1411 RODOLFO G. CAMPOS and ILIANA REGGIO: Consumption in the shadow of unemployment.

1412 PAUL EHLING and DAVID HAUSHALTER: When does cash matter? Evidence for private firms.

1413 PAUL EHLING and CHRISTIAN HEYERDAHL-LARSEN: Correlations.

1414 IRINA BALTEANU and AITOR ERCE: Banking crises and sovereign defaults in emerging markets: exploring the links.

1415 ÁNGEL ESTRADA, DANIEL GARROTE, EVA VALDEOLIVAS and JAVIER VALLÉS: Household debt and uncertainty: private consumption after the Great Recession.

1416 DIEGO J. PEDREGAL, JAVIER J. PÉREZ and A. JESÚS SÁNCHEZ-FUENTES: A toolkit to strengthen government budget surveillance.

1417 J. IGNACIO CONDE-RUIZ, and CLARA I. GONZÁLEZ: From Bismarck to Beveridge: the other pension reform in Spain.

1418 PABLO HERNÁNDEZ DE COS, GERRIT B. KOESTER, ENRIQUE MORAL-BENITO and CHRISTIANE NICKEL: Signalling fiscal stress in the euro area: a country-specific early warning system.

1419 MIGUEL ALMUNIA and DAVID LÓPEZ-RODRÍGUEZ: Heterogeneous responses to effective tax enforcement: evidence from Spanish firms.

1420 ALFONSO R. SÁNCHEZ: The automatic adjustment of pension expenditures in Spain: an evaluation of the 2013 pension reform

1421 JAVIER ANDRÉS, ÓSCAR ARCE and CARLOS THOMAS: Structural reforms in a debt overhang.

1422 LAURA HOSPIDO and ENRIQUE MORAL-BENITO: The public sector wage premium in Spain: evidence from longitudinal administrative data.

1423 MARÍA DOLORES GADEA-RIVAS, ANA GÓMEZ-LOSCOS and GABRIEL PÉREZ-QUIRÓS: The Two Greatest. Great Recession vs. Great Moderation.

1424 ENRIQUE MORAL-BENITO and OLIVER ROEHN: The impact of financial (de)regulation on current account balances.

1425 MAXIMO CAMACHO and JAIME MARTINEZ-MARTIN: Real-time forecasting US GDP from small-scale factor models.

1426 ALFREDO MARTÍN OLIVER, SONIA RUANO PARDO and VICENTE SALAS FUMÁS: Productivity and welfare: an application to the Spanish banking industry.

1427 JAVIER ANDRÉS and PABLO BURRIEL: Inflation dynamics in a model with firm entry and (some) heterogeneity.

1428 CARMEN BROTO and LUIS MOLINA: Sovereign ratings and their asymmetric response to fundamentals.

1429 JUAN ÁNGEL GARCÍA and RICARDO GIMENO: Flight-to-liquidity flows in the euro area sovereign debt crisis.

1430 ANDRĖ LEMELIN, FERNANDO RUBIERA-MOROLLÓN and ANA GÓMEZ-LOSCOS: Measuring urban agglomeration. A refoundation of the mean city-population size index.

1431 LUIS DIEEZ-CATALÁN and ERNESTO VILLANUEVA: Contract staggering and unemployment during the Great Recession: evidence from Spain. 
1501 LAURA HOSPIDO and EVA MORENO-GALBIS: The Spanish productivity puzzle in the Great Recession.

1502 LAURA HOSPIDO, ERNESTO VILLANUEVA and GEMA ZAMARRO: Finance for all: the impact of financial literacy training in compulsory secondary education in Spain.

1503 MARIO IZQUIERDO, JUAN F. JIMENO and AITOR LACUESTA: Spain: from immigration to emigration?

1504 PAULINO FONT, MARIO IZQUIERDO and SERGIO PUENTE: Real wage responsiveness to unemployment in Spain: asymmetries along the business cycle.

1505 JUAN S. MORA-SANGUINETTI and NUNO GAROUPA: Litigation in Spain 2001-2010: Exploring the market for legal services.

1506 ANDRES ALMAZAN, ALFREDO MARTÍN-OLIVER and JESÚS SAURINA: Securitization and banks' capital structure.

1507 JUAN F. JIMENO, MARTA MARTÍNEZ-MATUTE and JUAN S. MORA-SANGUINEITI: Employment protection legislation and labor court activity in Spain.

1508 JOAN PAREDES, JAVIER J. PÉREZ and GABRIEL PEREZ-QUIRÓS: Fiscal targets. A guide to forecasters?

1509 MAXIMO CAMACHO and JAIME MARTINEZ-MARTIN: Monitoring the world business cycle.

1510 JAVIER MENCÍA and ENRIQUE SENTANA: Volatility-related exchange traded assets: an econometric investigation.

1511 PATRICIA GÓMEZ-GONZÁLEZ: Financial innovation in sovereign borrowing and public provision of liquidity.

1512 MIGUEL GARCÍA-POSADA and MARCOS MARCHETTI: The bank lending channel of unconventional monetary policy: the impact of the VLTROs on credit supply in Spain.

1513 JUAN DE LUCIO, RAÚL MÍNGUEZ, ASIER MINONDO and FRANCISCO REQUENA: Networks and the dynamics of firms' export portfolio.

1514 ALFREDO IBÁÑEZ: Default near-the-default-point: the value of and the distance to default.

1515 IVÁN KATARYNIUK and JAVIER VALLÉS: Fiscal consolidation after the Great Recession: the role of composition.

1516 PABLO HERNÁNDEZ DE COS and ENRIQUE MORAL-BENITO: On the predictability of narrative fiscal adjustments.

1517 GALO NUÑO and CARLOS THOMAS: Monetary policy and sovereign debt vulnerability.

1518 CRISTIANA BELU MANESCU and GALO NUÑO: Quantitative effects of the shale oil revolution.

1519 YAEL V. HOCHBERG, CARLOS J. SERRANO and ROSEMARIE H. ZIEDONIS: Patent collateral, investor commitment and the market for venture lending.

1520 TRINO-MANUEL ÑíGUEZ, IVAN PAYA, DAVID PEEL and JAVIER PEROTE: Higher-order risk preferences, constant relative risk aversion and the optimal portfolio allocation.

1521 LILIANA ROJAS-SUÁREZ and JOSÉ MARÍA SERENA: Changes in funding patterns by Latin American banking systems: how large? how risky?

1522 JUAN F. JIMENO: Long-lasting consequences of the European crisis.

1523 MAXIMO CAMACHO, DANILO LEIVA-LEON and GABRIEL PEREZ-QUIROS: Country shocks, monetary policy expectations and ECB decisions. A dynamic non-linear approach.

1524 JOSÉ MARÍA SERENA GARRALDA and GARIMA VASISHTHA: What drives bank-intermediated trade finance? Evidence from cross-country analysis.

1525 GABRIELE FIORENTINI, ALESSANDRO GALESI and ENRIQUE SENTANA: Fast ML estimation of dynamic bifactor models: an application to European inflation.

1526 YUNUS AKSOY and HENRIQUE S. BASSO: Securitization and asset prices.

\section{BANCODEESPAÑA}

\author{
Eurosistema
}

Unidad de Servicios Auxiliares

Alcalá, 48 - 28014 Madrid

E-mail: publicaciones@bde.es www.bde.es 